\title{
SISMOESTRATIGRAFIA CORRELATIVA ENTRE AS BACIAS DE TUCANO SUL E RECÔNCAVO
}

\author{
CORRELATIVE SEISMOSTRATIGRAPHY BETWEEN TUCANO SUL AND RECONCAVO BASINS
}

Nair Lorena Gaspar NONATO; Michael HOLZ

Universidade Federal da Bahia. Departamento de Geofísica do Instituto de Geociências. Avenida Adhemar de Barros, s/n. Campus Universitário de Ondina. Salvador - BA. E-mails: loregeologia@gmail.com; michael.holz@ufba.br

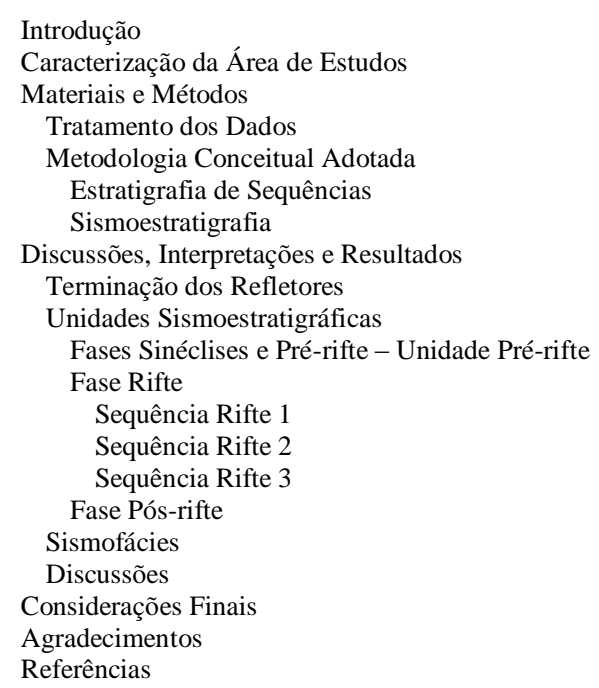

RESUMO - A estratigrafia de sequências, aplicada a bacias do tipo rifte, consiste em uma adaptação do modelo clássico que se encontra em plena fase de consolidação. Os fundamentos norteadores da estratigrafia de sequências se aplicam em qualquer contexto de sedimentação e são fundamentais para entender a história deposicional de uma bacia. O presente trabalho teve como objetivo estudar o arcabouço sismoestratigráfico de Tucano Sul, sob o viés da estratigrafia de sequências aplicada a bacias rifte, a fim de correlacionar esse estudo com a bacia do Recôncavo. A partir da integração das seções sísmicas compostas associadas a dados de perfis geofísicos e litológicos de 15 poços, foi realizado o tratamento desses dados no software de interpretação sísmica IHS Kindle. A análise sismoestratigráfica de Tucano Sul aqui desenvolvida, envolveu a interpretação das terminações de refletores, definição das unidades sismoestratigráficas a partir do mapeamento de superfícies-chaves, além da caracterização das principais sismofácies. Como resultado, foram individualizadas cinco unidades sismoestratigráficas, segundo o modelo aqui adotado: unidade Pré-rifte, Rifte 1, Rifte 2, Rifte 3 e unidade Pós-rifte. Foram definidas cinco sismofácies, SF1 a SF5, cada qual com seus parâmetros característicos. Ao fim, propôsse uma discussão acerca da correlação sismoestratigráfica com a bacia do Recôncavo. Para o intervalo rifte, Tucano Sul apresentou uma sequência sismoestratigráfica a menos comparada com a bacia do Recôncavo, indicando importante evento erosivo durante o seu desenvolvimento.

Palavras-chave: Estratigrafia de sequências, Sismoestratigrafia, Rifte.

ABSTRACT - The sequence stratigraphy applied to rifte basins consists of an adaptation of the classic model that is in full consolidation phase. The guiding principles of sequence stratigraphy are applied in any sedimentation context. They are fundamental to understanding the depositional history of a basin. The present work had as objective to study the seismic stratigraphy framework of Tucano Sul basin under the bias of sequence stratigraphy applied to rifte basins in order to correlate this study with the Recôncavo basin. From the integration of the seismic sections associated to the data of 15 wells (geophysical and lithological profiles) the data were processed in the IHS Kindle seismic interpretation software. The seismic stratigraphic analysis involved the interpretation of reflector terminations, definition of the seismostratigraphic units from the mapping of key surfaces as well as the characterization of the major seismic facies. As a result, five seismostratigraphic units were identified according to the model adopted here: Pre-rift unit, Rifte 1, Rifte 2, Rifte 3 and Post-rift unit. Five seismic facies were defined, SF1 to SF5, each with its characteristic parameters. At the end, a discussion was proposed about the seismostratigraphic correlation with the Recôncavo basin. For the rifte interval, Tucano Sul presented a seismostratigraphic sequence less than the Recôncavo basin, indicating an important erosive event during its development. Keywords: Sequence stratigraphy, Seismostratigraphy, Rift.

\section{INTRODUÇÃO}

A Estratigrafia de Sequências constitui o fundamental paradigma da moderna geologia sedimentar. Consiste em uma ferramenta de análise estratigráfica muito poderosa capaz de recontar a história de preenchimento de uma bacia, levando em consideração seus fundamentos norteadores. Sua premissa básica entende que, em uma bacia, o regime de 
sedimentação é controlado pela interação entre a taxa de suprimento sedimentar e a taxa de criação de espaço de acomodação.

No modelo básico da estratigrafia de sequências, baseado na sedimentação em bacia de margem passiva, os tratos de sistemas clássicos se desenvolvem seguindo uma ordem característica durante um ciclo de variação do nível de base, o qual é controlado principalmente pelo nível eustático relativo. Em bacias rifte, por outro lado, esse controle é feito pela tectônica que, em um regime típico de movimentação de falhas produz um estilo tectônico composto por um sistema complexo de meio-grábens responsável pela criação/destruição de espaço. Assim, algumas adaptações no modelo clássico precisam ser feitas para aplicar essa metodologia em ambiente rifte.

Nesse contexto, Prosser (1993) foi o primeiro trabalho a demonstrar que é preferível identificar e descrever os sistemas deposicionais em termos de fácies e padrões de empilhamento e interpretando-os em termos de mudanças locais do nível de base (neste caso, o nível do lago rifte). Holz et al. (2014, 2017, 2018) propuseram um modelo de bacia rifte com um regime de "subsidência pontuada", marcado por períodos em que a subsidência tectônica cessa. A assinatura estratigráfica da bacia será marcada por diversas inconformidades dentro do intervalo rifte, as quais segregam estratos geneticamente relacionados a um estágio tectônico do rifteamento. Assim, o que é genericamente chamado de "a sucessão rifte" de uma bacia, os autores sugerem ser melhor denominado por "sucessões de riftes", por ter várias discordâncias intra-rifte limitando suas respectivas sequências rifte.

Nesse sentido, o objetivo específico desse trabalho foi aplicar essa metodologia de estudo de bacias rifte em Tucano Sul, caracterizando o arcabouço sismoestratigráfico da bacia, com o objetivo geral de correlacionar Tucano Sul com a bacia do Recôncavo. Essa comparação foi realizada discutindo as similaridades e discrepâncias entre tais bacias e as implicações envolvidas nisso. Estas análises foram confrontadas com estudos similares desenvolvidos na bacia do Recôncavo, como o trabalho de Vilas Boas (2016).

\section{CARACTERIZAÇÃO DA ÁREA DE ESTUDO}

A Bacia de Tucano está localizada na região nordeste do Brasil e representa a porção intermediária do rifte abortado RecôncavoTucano-Jatobá, originado no processo extensional que formou o Atlântico Sul. A bacia encontra-se dividida em três compartimentos, Tucano Sul, Central e Norte, separados, entre si, pelos cursos dos rios Itapicuru e Vaza-Barris, respectivamente (Magnavita et al., 2003). O polígono da área de estudo inclui a bacia de Tucano Sul, e uma porção nordeste da bacia do Recôncavo que se conecta com a Bacia de Tucano (Figura 1). Para este estudo, foram utilizados dados de 15 poços e 39 linhas sísmicas 2D localizados no polígono da figura 1.

A bacia de Tucano Sul é estruturalmente caracterizada por um semigráben basculado para sudeste, ocupando uma área de cerca de 7.000 km2 (Magnavita et al., 2003). É limitada a norte pela zona de acomodação do rio Itapicuru; a leste pela falha de Inhambupe; a sul pelo Alto de Aporá; e a oeste, o limite se dá com o embasamento cristalino. Seu arcabouço estrutural caracteriza-se por falhas organizadas em estilo dominó, orientadas $\mathrm{N} 25 \mathrm{oE}$, mergulhando para oeste, tornando-se mais profundo para leste, onde atinge mais de $7 \mathrm{~km}$ de profundidade no Baixo de Inhambupe. Tucano Sul e Central foram instaladas sobre a borda nordeste do Cráton do São Francisco, tendo como embasamento ortognaisses migmatíticos, a oeste-sudoeste e sudeste; rochas metavulcanosedimentares do greenstone belt do Rio Itapicuru, a oeste; metassedimentos da cobertura cratônica Estância, a noroeste e leste-nordeste; e rochas sedimentares da Bacia Palmares, a leste (Silva et al., 2007).

A litoestratigrafia destas bacias foi formalizada inicialmente por Viana et al. (1971, apud Silva et al., 2007). Mais tarde, foram propostas colunas individualizadas para cada bacia. $\mathrm{O}$ preenchimento sedimentar foi divido em três fases denominadas de pré-rifte, sin-rifte e pós-rifte, melhores individualizadas em Tucano-Sul e Recôncavo. Costa et al. (2007) propuseram o fatiamento litoestratigráfico do arcabouço de Tucano Sul em quatro supersequências (sequências de segunda ordem) e suas respectivas sequências de terceira ordem componentes: a Supersequência Paleozoica (fase sinéclise), as Supersequências Jurocretáceas (relacionadas aos estágios pré-rifte e rifte), a Supersequência Pós-rifte, além das Sequências do Cenozoico, o que resultou formalmente na carta estratigráfica mais recente da bacia. 

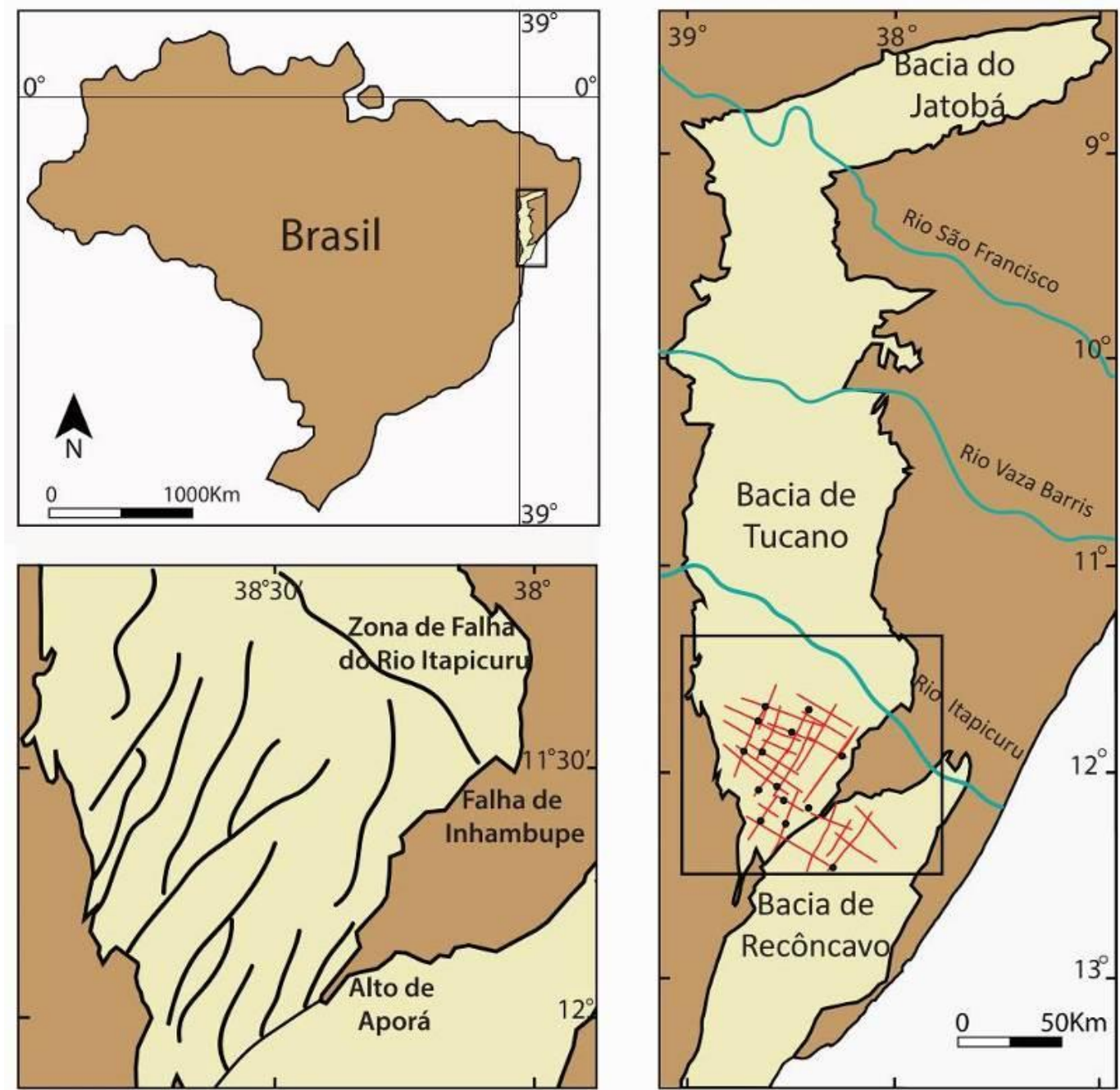

Figura 1 - Mapa de localização da área de estudo, com a disposição dos dados utilizados ( poços em preto e linhas sísmicas em vermelho) e a representação do arcabouço estrutural da bacia de Tucano Sul.

\section{MATERIAIS E MÉTODOS}

\section{Tratamento dos Dados}

A primeira etapa se caracterizou pela conferência e arquivamento dos dados de poços e sísmica no banco de dados do GETA. Detectouse que todos os poços traziam arquivos com os perfis em formato DLIS ou LIS, essencial para a amarração dos poços nas linhas sísmicas. Quanto às linhas sísmicas, foi realizada uma verificação das 39 linhas no software SEISEE com o objetivo de checar se o número de traços em cada linha coincidia com o valor do CDP (Common Depth Point) final mais 1 , o que foi confirmado em todas elas.

Com os dados conferidos, procedeu-se à criação de um Novo Projeto (intitulado Tucano Sul) no IHS KINGDOM, software de interpretação sísmica disponível no GETA/UFBA para o tratamento e intepretação sismoestratigráfica dos dados dessa pesquisa. Para criar esse projeto, verificou-se no arquivo UKOOA qual o sistema geográfico de coordenadas adotado no levantamento sísmico em questão, para então defini-lo no programa, sendo identificado o UTM WGS 84. Num primeiro momento foi feito o carregamento dos 15 poços. O carregamento foi realizado a partir dos arquivos AGP (Arquivo Geral de Poço) de cada poço e seu respectivo perfil composto, os quais contém a coluna litológica construída a partir de amostras de calha, topo e base das unidades, localização e uma série de dados relativos ao poço. Em um momento posterior, carregou-se as 39 linhas sísmicas no projeto Tucano Sul. Primeiramente, elas passaram por análise no software SEISEE, para a análise das coordenadas da fonte e do CDP, com o objetivo de checar se eram razoavelmente próximas e analisou-se também o intervalo de amostragem em cada uma das linhas sísmicas para que elas pudessem ser carregadas conjuntamente. Dessa análise, constatou-se que das 39 linhas, parte delas possuía intervalo de amostragem de 2 
segundos (da linha 5 até a 9 e da linha 23 até a 29) e outra parte possuía intervalo de amostragem de 4 segundos (da linha 1 até a 4, da linha 10 até a 22 e a linha 30). Quanto às coordenadas da fonte e do CPD, apenas as linhas de 01 até $04,9,10,13$ e 19 apresentaram diferenças aceitáveis entre elas. Por conta disso, para as demais linhas sísmicas, cujos valores de CPD e fonte foram muito discrepantes, adotou-se o próprio valor do CPD para a coordenada da fonte. As linhas 31 a 39 remanescentes foram importadas de projeto já existente.

$\mathrm{O}$ passo metodológico subsequente envolveu a transformação dos arquivos que contém os dados geofísicos armazenados no formato LIS ou DLIS para o formato LAS, que é o formato aceito pelo programa. Essa transformação foi feita no software LOG TOOBOX e, nesse procedimento, um dos poços apresentou incompatibilidade de recuperação e parte dele foi perdida no processo. Feita a conversão, pôde-se então carregar os perfis geofísicos dos poços no IHS KINGDOM e assim proceder para a amarração deles. Antes de iniciar a amarração, foi necessário corrigir pontos em que as curvas DT (Sônico) e RHOB (Densidade) usadas na amarração apresentavamse "estouradas", provável resultado de eventuais desabamentos da parede do poço.

Com os perfis de poços carregados, a etapa seguinte consistiu na correlação entre os dados de poço (perfis) e os dados sísmicos. Para tal correlação foi necessário construir sismogramas sintéticos, com o fim de converter os dados associados à profundidade dos perfis geofísicos em tempo, igualando dessa forma, a unidade vertical estudada. Para a construção dos sismogramas, inicialmente foram separados os poços que possuíam os perfis sônico e de densidade, que representam, respectivamente e de forma aproximada, a velocidade sísmica e a densidade das camadas geológicas.

Dos 15 poços analisados, apenas três poços não possuíam nem sônico, nem densidade. Apenas para esses poços, a amarração teve que ser feita utilizando-se o perfil de resistividade para estimar o tempo de propagação da onda e assim amarrar os poços na sísmica.

O software de interpretação sísmica estimou os traços sintéticos, a partir de algoritmos e cálculos matemáticos, criando um sismograma para cada poço. A partir daí, foram realizadas comparações entre o sismograma sintético e os sismogramas reais das seções sísmicas, buscando correlacionar os picos de reflexões (maiores amplitudes) positivas e negativas entre as camadas. Esse ajuste pôde ser feito com a ferramenta GeoSyn existente no IHS KINGDOM. A figura 2 mostra a janela de ajuste onde foi efetuada a comparação entre o dado sísmico original, obtido nesse caso da linha sísmica 14 , com o sismograma sintético construído para o poço 01 , que corta essa linha. Nessa imagem observa-se que com essa comparação obteve-se um coeficiente de correlação de 0,1168 , valor razoável para amarrar esse poço nessa posição vertical.

Por fim, com o intuito de auxiliar a interpretação sísmica, o procedimento preparativo final executado no IHS KINGDOM foi o cálculo dos atributos sísmicos mais úteis, dentre eles: amplitude instantânea, TecVA (Técnica Volume de Amplitudes) e fase instantânea. O atributo de amplitude instantânea retrata a intensidade do contraste de impedância acústica (que reflete a mudança de propriedades físicas, elásticas e de densidade) entre as camadas geológicas. $\mathrm{O}$ atributo de fase instantânea é útil na identificação de continuidade de refletores nas seções sísmicas, e sua utilização se mostrou importante na identificação das terminações de refletores, do padrão de inclinação das camadas sedimentares, falhas e padrão geométrico interno das camadas. E o atributo de TecVa, também chamado de pseudorelief, representa reflexões sísmicas de dados pós-empilhados com aparência de relevo topográfico, a partir de transformações matemáticas feitas no dado original. A interpretação deste atributo foi muito importante na identificação de planos de falhas, descontinuidades e estruturas associadas à mudança de sismofácies e/ou unidades sísmicas.

\section{Metodologia Conceitual Adotada}

Com os dados todos tratados, a fase de intepretação sismoestratigráfica pôde ser iniciada e ela consistiu no trabalho intelectual propriamente dito. Nesta fase, duas ferramentas metodológicas foram utilizadas: o arcabouço conceitual da estratigrafia de sequências e os princípios e técnicas da sismoestratigrafia.

\section{Estratigrafia de Sequências}

A estratigrafia de sequências tem por objetivo analisar, compreender e mapear a resposta sedimentar frente às diferentes variações do nível de base. O nível de base sobe e desce a depender das variáveis alogênicas: clima, aporte e tectônica, além da eustasia para as bacias oceânicas. Como estamos tratando de bacias rifte 
continentais neste trabalho, sem comunicação com o oceano, a eustasia é desconsiderada. Para fins de simplificação e aplicabilidade, o aporte é adotado como constante, segundo a concepção de trabalho adotada pela estratigrafia. Da mesma maneira, o clima, só é considerado em detalhe quando se estuda bacias tectonicamente semelhantes com paleoclimas distintos entre si, o que não é o caso de Tucano Sul e Recôncavo. Por último a tectônica, esta sim, exerce grande influência na criação e destruição de espaço de acomodação em uma bacia rifte conforme assimilado pelos modelos comentados neste trabalho.

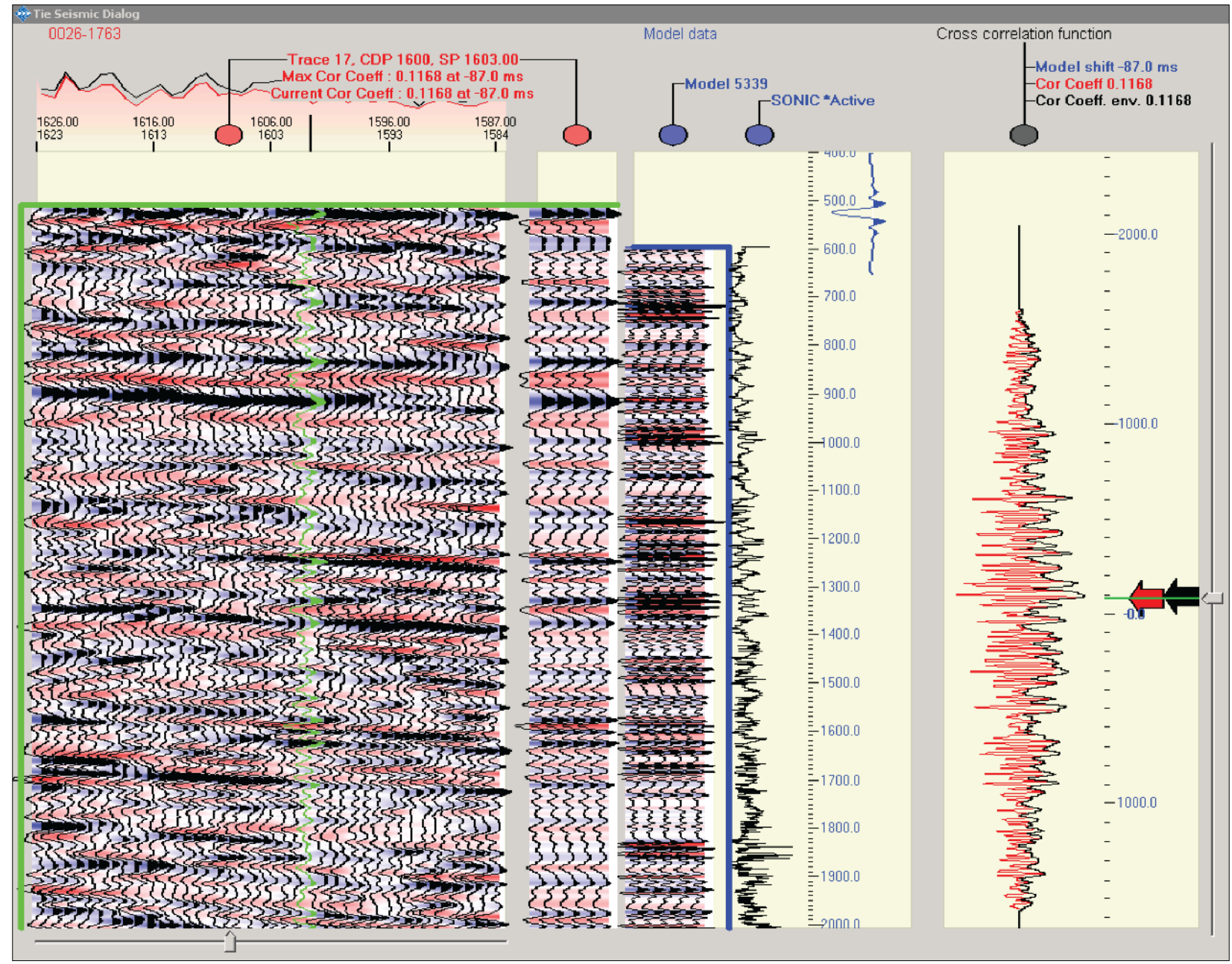

Figura 2 - Janela de ajuste do software IHS Kingdom utilizada na amarração do poço na linha sísmica, com a indução do coeficiente de correlação obtido na amarração do poço 1 à linha 14.

As bacias rifte são bacias tectonicamente ativas resultantes do processo de extensão crustal. São depressões assimétricas estruturadas por falhas normais de alto ângulo que formam um sistema complexo de meios-grábens. A criação e destruição de espaço de acomodação nesse tipo de bacia ocorre principalmente pela movimentação das falhas que produz subsidência no hangingwall e soerguimento no footwall, criando e destruindo espaço sincronicamente.

Primeiramente, Lambiase (1990) propôs para bacias rifte um modelo baseado na sucessão de sistemas deposicionais. Segundo ele, inicialmente uma ampla bacia com algumas pequenas falhas é preenchida por sedimentos fluviais. $\mathrm{Na}$ fase seguinte, tem-se uma maior subsidência, com maior geração de espaço e menor aporte sedimentar devido à divergência das drenagens gerada pelo soerguimento das ombreiras. Nessa fase, um sistema lacustre é instalado, e aos poucos uma sedimentação flúviodeltaica começa a desembocar nesse lago, até que estes sistemas deposicionais dominem na bacia. Esse aumento da contribuição siliciclástica se deve ao estabelecimento das drenagens e à diminuição da atividade tectônica. No estágio final, a sedimentação tende a ultrapassar os limites da bacia em razão da subsidência térmica e denudação dos altos (ombreiras) que limitavam o rifte (Figura 3).

Prosser (1993) propôs um modelo de fatiamento da sucessão de um rifte baseado na 
configuração das reflexões e fácies sísmicas e na interpretação dos padrões de empilhamento. A autora sugere o termo "trato de sistemas tectônico" (TST) para individualizar as diferentes fases evolutivas identificadas no arcabouço de um rifte. Ela propôs quatro tratos de sistemas relacionados a cada fase tectônica e seus respectivos padrões de empilhamento. Ela chama atenção, contudo, que isso pode variar de rifte para rifte de acordo com as particularidades de cada bacia.

Holz et al. (2017), inspirados no trabalho de
Prosser (1993) e no modelo tripartido de Gawthorpe \& Leeder (2000), propuseram dois modelos estratigráficos de sequências com suas fases tectono-estratigráficas. Para os autores, a depender da história tectônica regional, as sucessões rifte podem apresentar dois tipos distintos de subsidência: "Subsidência Gradual" ou "Subsidência Pontuada". Os riftes com "subsidência gradual" são formados por um regime de subsidência mais gradual e uniforme, eles não apresentam hiatos significativos no seu registro estratigráfico.

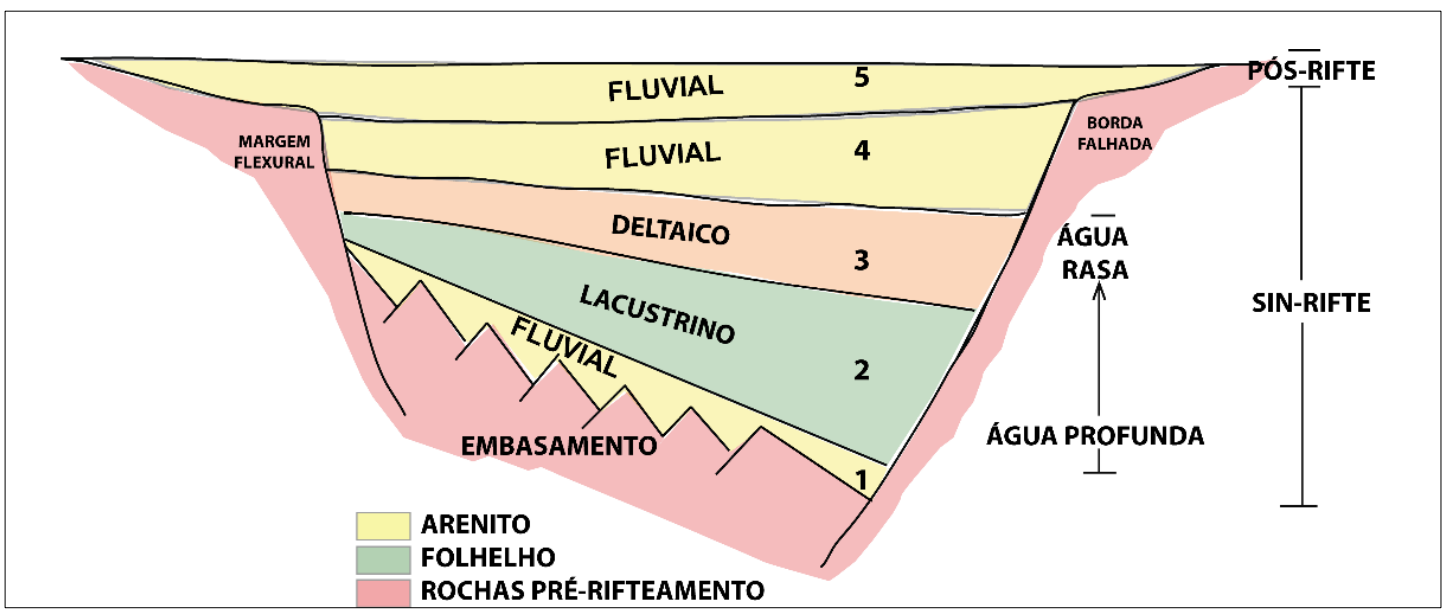

Figura 3 - Seção esquemática de um meio-gráben, contendo a sucessão estratigráfica com o domínio de cinco ambientes sedimentares das fases pré-rifte ao pós rifte, idealizada por Lambiase (1990).

Eles representam o modelo ideal de evolução de um rifte e por isso são menos comuns. Eles têm uma fase inicial de baixa taxa de subsidência, seguida de uma época de subsidência crescente por rifteamento intenso e, finalmente, atingindo uma fase decrescente, quando o processo de rifteamento chega ao fim. Assim, inicialmente, o espaço criado é ainda incipiente, gerando a progradação de sistemas flúvio-deltaicos (trato tectônico de início de rifte-TTIR). Com o aumento progressivo da deformação, o aporte não consegue suprir o espaço de acomodação criado, gerando a retrogradação de sistemas lacustres (trato tectônico de desenvolvimento de rifte-TTDR). No estágio final, ocorre a progradação de sistemas flúvio-deltaicos já que a criação de espaço é decrescente com o fim do rifteamento (trato tectônico de final de rifte-TTFR).

Em contrapartida, uma bacia rifte com um regime de "subsidência pontuada" é marcada por períodos em que a subsidência tectônica cessa. Neste cenário tectônico, a assinatura estratigráfica da bacia será marcada por diversas inconformidades dentro do intervalo rifte. Após a fase inicial caracterizada pelos meio-grábens incipientes e baixas taxas de acomodação
(TTIR), segue-se um período de retomada crescente da subsidência, com aumento de espaço de acomodação, registrando o TTDR. Ao se aproximar de um novo período de quietude tectônica, a taxa de acomodação diminui e o regime de sedimentação será novamente progradacional, registrando o TTFR. Num momento posterior, uma nova movimentação tectônica ocorre e o rearranjo do substrato produz um aumento no espaço de acomodação no interior do rifte e expõe à erosão as margens do rifte. Esse aumento do espaço promove a deposição de um novo TTDR, o qual é seguido por um novo TTFR, este associado ao estágio de calmaria tectônica subsequente. Essa mudança de regime progradacional do TTDR para retrogradacional do TTFR pode formar a superfície de máximo rifteamento (SMR) entre os dois tratos, marcando justamente a mudança de regime.

O resultado desse tipo de subsidência pontuada (Figura 4) é uma sucessão de riftes com várias inconformidades, cada uma encerrando um TTFR. Os autores chamam a atenção para o fato de que uma bacia com várias inconformidades intra-rift pode ser adjacente e bastante próxima a uma bacia sem discordâncias internas. 


\section{Sismoestratigrafia}

A Sismoestratigrafia, por sua vez, consiste na aplicação de conceitos e técnicas de mapeamento de terminações estratais e de superfícies estratigráficas em imagens sísmicas (Vail et al., 1977). A Sismoestratigrafia entende primeiramente que as reflexões sísmicas são geradas em superfícies que separam estratos de rochas com contrastes de impedância acústica e que possuem um forte caráter cronoestratigráfico.

A metodologia de interpretação sismoestra-

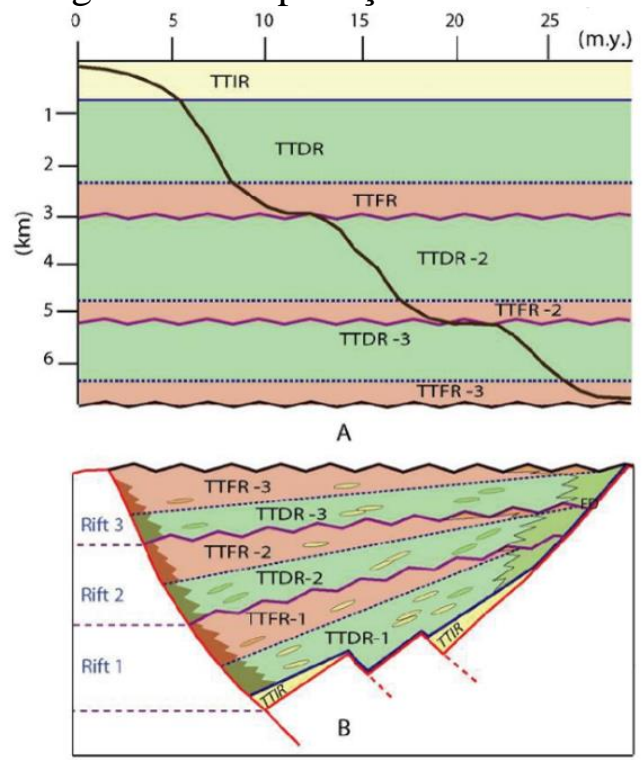

tigráfica empregada no presente trabalho consistiu inicialmente na análise das reflexões e - das terminações de refletores sísmicos.

As terminações dos refletores são os limites que se fundem ou terminam contra refletores superiores ou inferiores. Estas terminações se constituem em um dos principais critérios para definição dos limites de uma sequência deposicional (Vail et al., 1977), pois se correlacionam diretamente com as terminações dos estratos depositados.

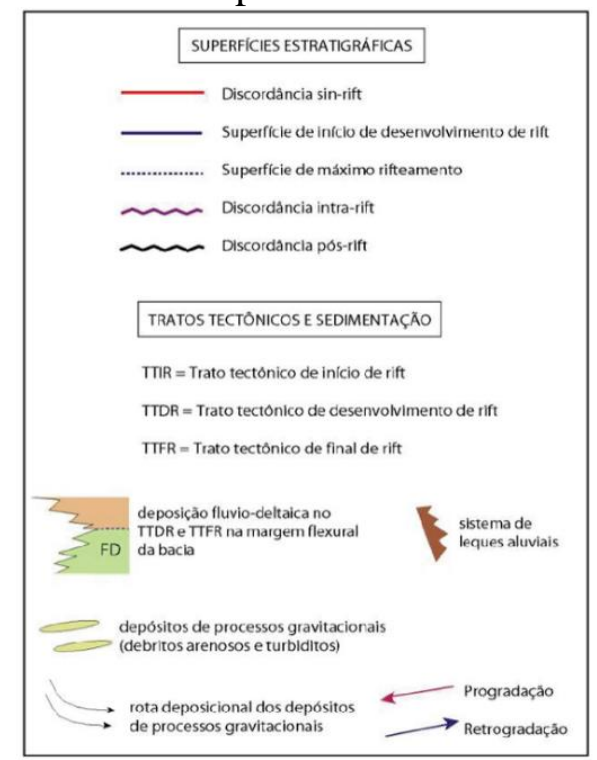

Figura 4- Ilustração do modelo de "subsidência pontuada" proposta por Holz et al. (2017). (A) mostra uma curva de subsidência hipotética; (B) ilustra o arcabouço estratigráfico resultante. O TTIR é restrito e apresenta pequenas espessuras.

As principais terminações utilizadas na interpretação dos refletores são (Figura 5):

- Onlap: quando a reflexão sísmica inicialmente horizontal termina que progressivamente sobre uma superfície deposicional inicialmente inclinada.

- Downlap: quando a reflexão sísmica termina mergulho abaixo sobre uma superfície com menor inclinação ou horizontal.

- Toplap: reflexões que terminam lateralmente e de forma assintótica ao limite superior.

- Truncamento Erosivo: terminação de estrato contra superfície erosiva sobrejacente.
Mapeadas estas terminações foi possível definir os limites das sequências sísmicas. As sequências sísmicas reúnem pacotes de refletores concordantes separados por superfícies de descontinuidades e são interpretadas como sequências deposicionais.

Nesta pesquisa, após a definição das sequências sísmicas, foi feita uma análise das sismofácies constituintes das sequências sísmicas. Uma sismofácies é uma unidade sísmica tridimensional mapeável, composta por um grupo de refletores cujos parâmetros diferem do conjunto de refletores adjacentes (Vail et al., 1977).

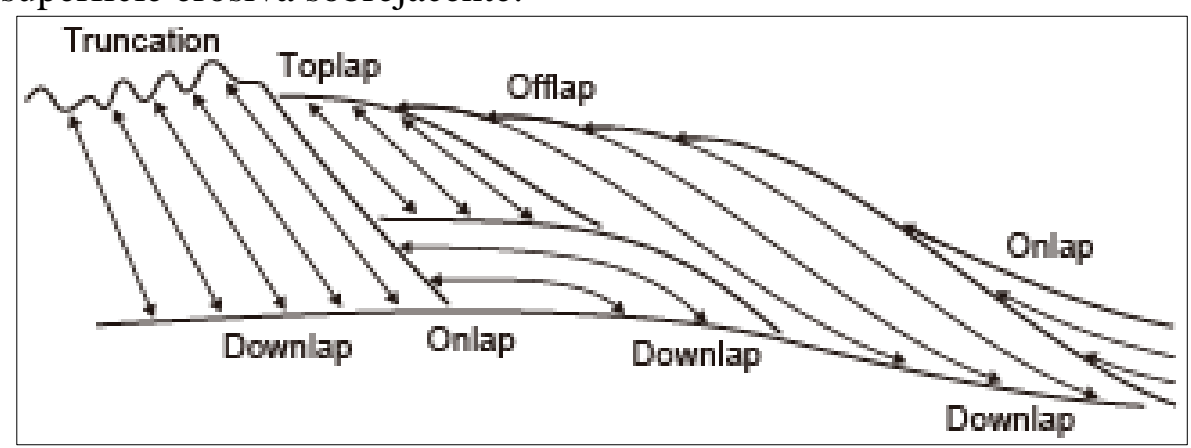

Figura 5- Tipos de terminações de refletores diretamente relacionadas às terminações estratais (Fonte: retirada de Catuneanu 2006, apud Emery \& Myers, 1996). 
Ela é descrita conforme uma série de parâmetros, tais como sua configuração de refletores, amplitude, continuidade, frequência e geometria interna e externa (Figura 6). A identificação desses parâmetros permite propor uma interpretação do ambiente deposicional em que a fácies sísmica foi depositada. Além disso, correlacionando a sísmica com os dados de poços foi possível sugerir os principais litotipos associados a algumas das sismofácies identificadas.

Com a análise sismoestratigráfica pronta, foram construídas seções sísmicas compostas para integralizar a interpretação desenvolvida tanto das unidades sismoestratigráficas, como das sismofácies.

Foram feitos também mapas de espessura sísmica de cada uma das sequências mapeadas, cujo objetivo foi estimar a distribuição e espessura das sequências e a posição dos depocentros de cada uma delas, para entender melhor a história deposicional da bacia.

Ao fim, fez-se uma discussão acerca da comparação do arcabouço sismoestratigráfico de Tucano Sul e Recôncavo, objetivo geral deste trabalho.

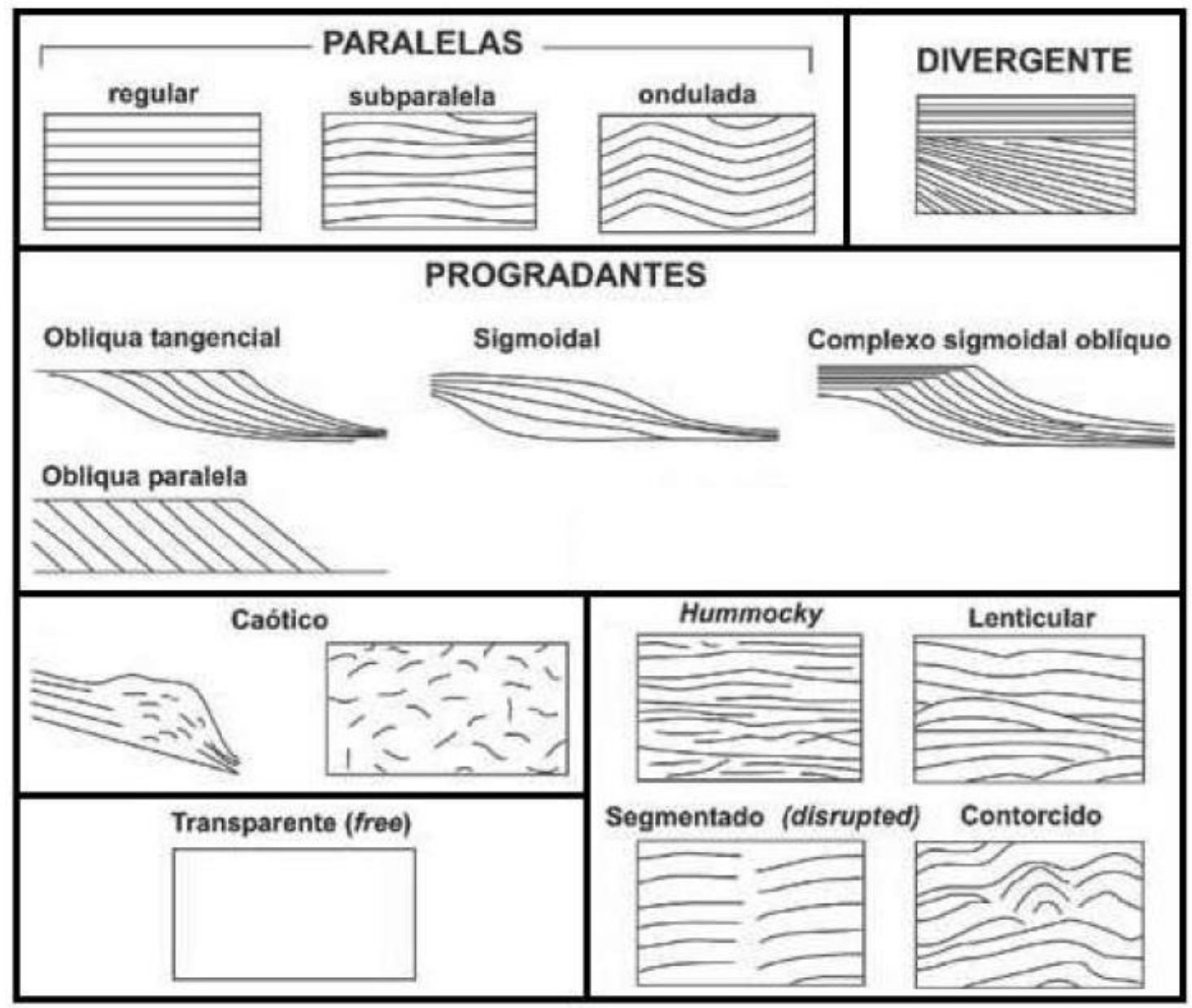

Figura 6 - Principais configurações internas e externas de fácies sísmicas. Fonte: Modificado de Vail \& Mitchum (1977).

\section{DISCUSSÕES, INTERPRETAÇÕES E RESULTADOS}

\section{Terminação dos Refletores}

Para realizar a análise sismoestratigráfica da área de estudo, inicialmente estabeleceu-se quais seriam as linhas sísmicas com melhor imageamento, parte delas dip, outra parte strike. Primeiro foram interpretadas essas seções-piloto e depois extrapoladas para as demais linhas sísmicas disponíveis.

Importou-se para o software o arquivo shapfile contendo o arcabouço estrutural da área de estudo e foram caracterizadas as principais falhas regionais e as falhas menores em sísmica. A análise sismoestratigráfica inicial consistiu em analisar os refletores e demarcar suas terminações aparentes (Figura 7), seguindo os princípios da sismoestratigrafia.

Nas seções strike, a identificação das terminações dos refletores (downlap, onlap, toplap $e$ truncamentos) foi um pouco mais complicada. Os padrões dos refletores nesse sentido da bacia são principalmente paralelos, podendo-se reconhecer alguns truncamentos e 


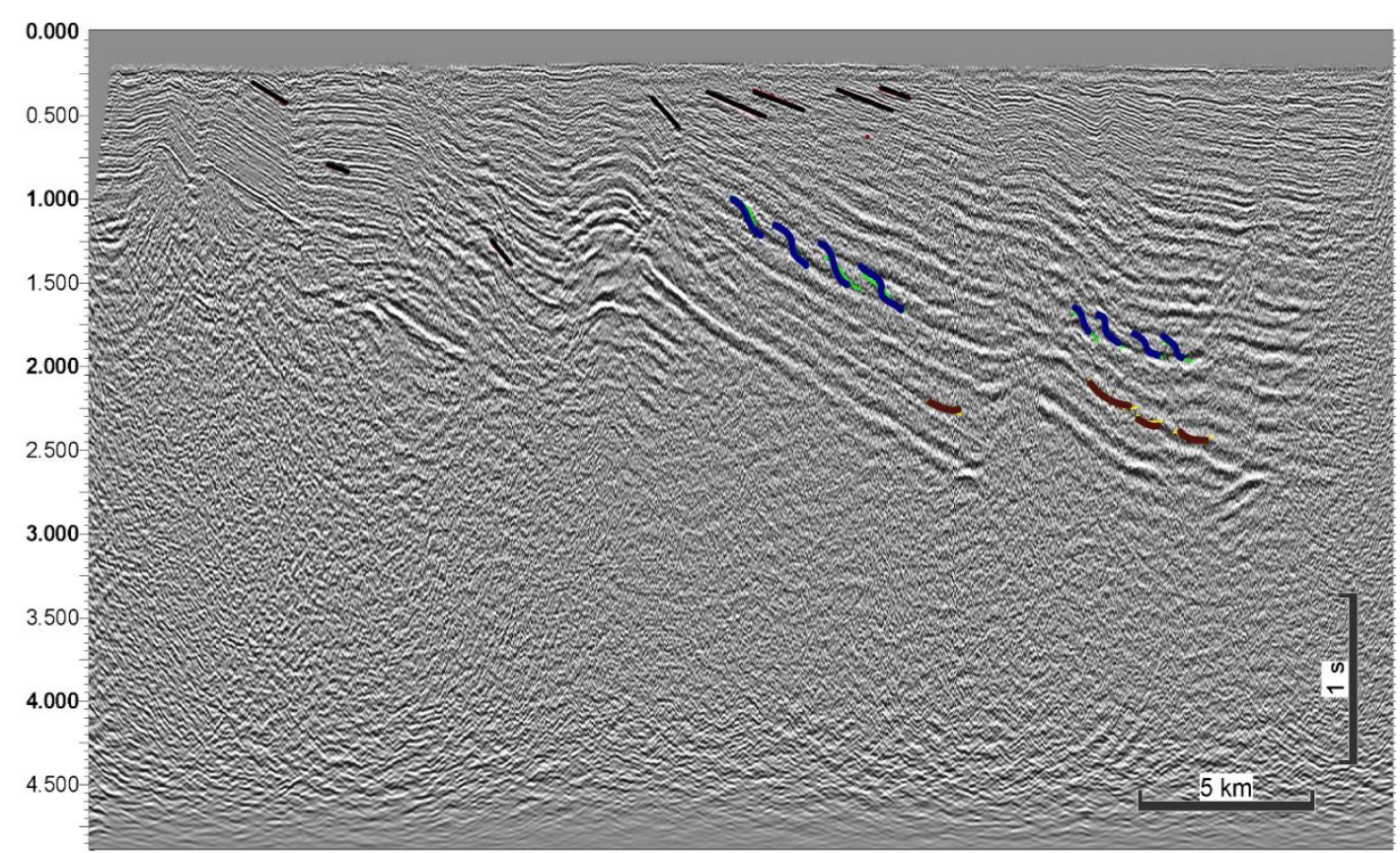

Figura 7 - Linha sísmica 24 com algumas terminações de refletores mapeadas. Em preto, truncamentos; em azul downlaps; e em marrom alguns onlaps.

concordâncias em geral com boa continuidade.

A presença de zonas de falhas dificultou a demarcação das terminações em vários pontos. Por outro lado, nas seções dip, o reconhecimento das terminações dos refletores foi menos complicado.

Os padrões de refletores mais comuns foram os paralelos e subparalelos, em geral com boa continuidade, os caóticos e livres de reflexão. A amplitude e a frequência dos refletores alternam entre alta e baixa.

\section{Unidades Sismoestratigráficas}

Em uma linha sísmica, uma sucessão de terminações de refletores ao longo de uma superfície pode definir o limite de base ou de topo de uma unidade sismoestratigráfica - que pode constituir uma sequência sísmica ou parte dela. Desse modo e de acordo com as seções sísmicas, foram definidas em sísmica cinco unidades sismoestratigráficas na área de estudo, denominadas da base para o topo de unidade pré-rifte (Pré-rifte), sequência rifte 1 (Rifte 1), sequência rifte 2 (Rifte 2), sequência rifte 3 (Rifte 3 ) e unidade pós-rifte (Pós-rifte).

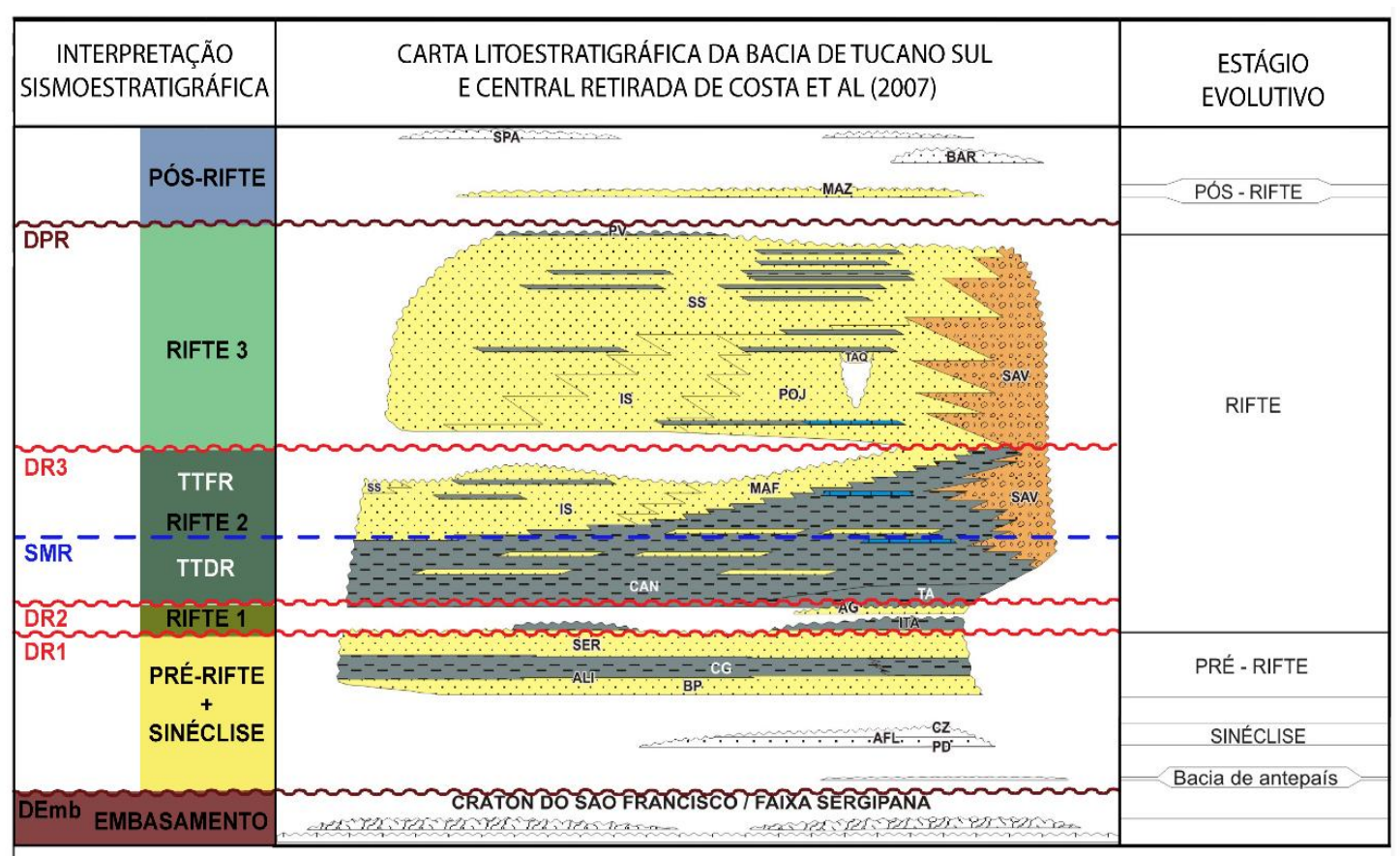

Figura 8 - Diagrama representativo relacionando a interpretação estratigráfica desenvolvida para a bacia de Tucano Sul com a sucessão litoestratigráfica proposta por Costa et al. (2007) para a mesma. 
Para fins de comparação e entendimento do modelo aqui adotado, construiu-se um diagrama composto pela carta cronoestratigráfica proposta por Costa et al. (2007) para a bacia de Tucano Sul e as superfícies sismoestratigráficas identificadas neste trabalho (Figura 8).
Nesse diagrama, até certo ponto, as superfícies sismoestratigráficas não necessáriamente possuem as mesmas idades das formações litoestratigráficas correlacionadas. Esse diagrama foi confeccionado apenas para representar a interpretação aqui desenvolvida.

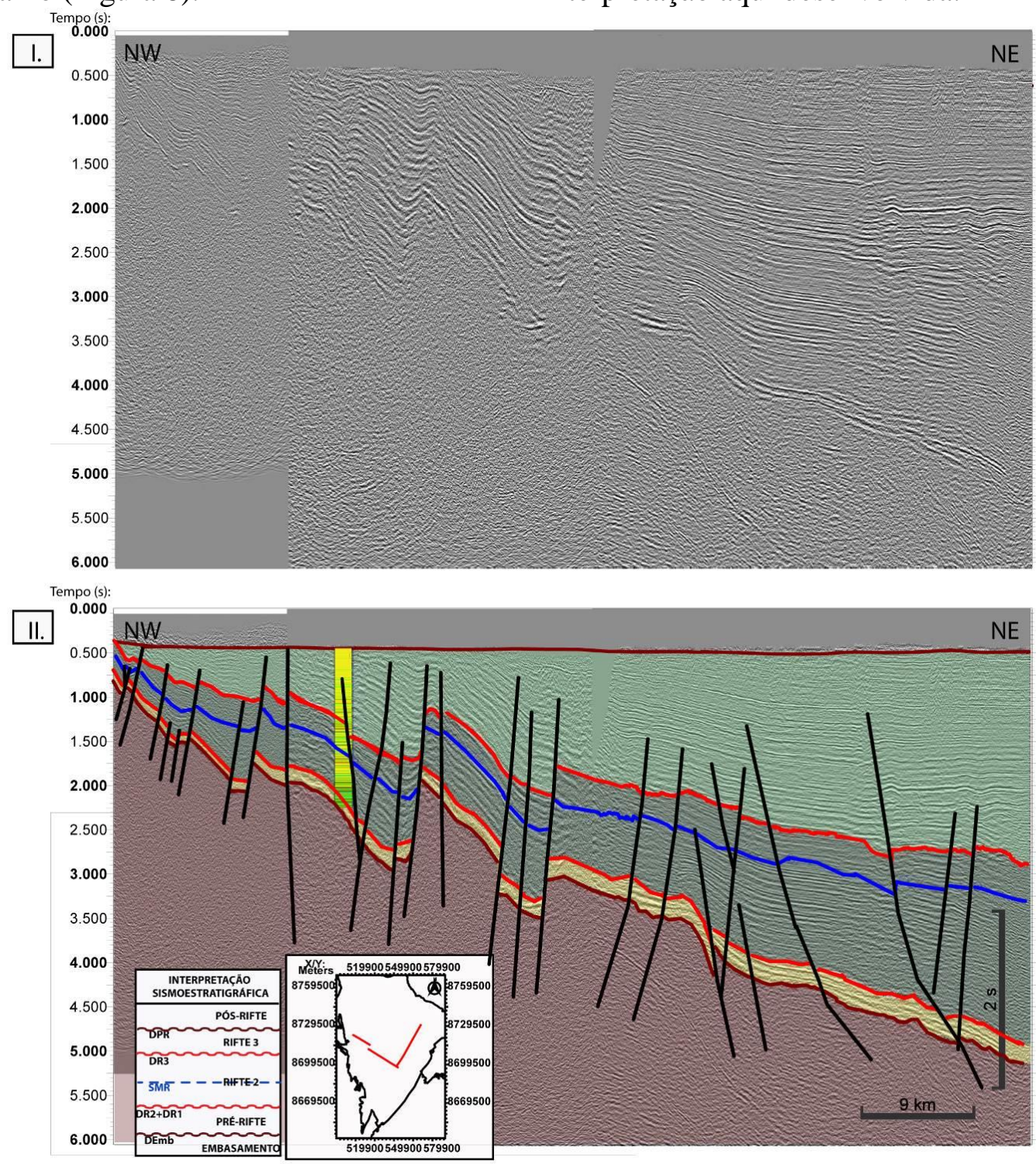

Figura 9 - Seção sísmica composta orientada dip-strike: (I.) não interpretada; (II.) com as unidades sismoestratigráficas interpretadas. Pode-se ver o caráter plano-paralelo no padrão de refletores da unidade sísmica Pré-rifte sobreposta ao embasamento.

\section{Fases Sinéclises e Pré-rifte - Unidade Pré-rifte}

A unidade sísmica Pré-rifte é limitada na base pela discordância do embasamento (DEmb) e no topo pela discordância rifte 1 ou discordância rifte 2 (DR1 ou DR2), a depender da preservação ou não da sequência Rifte 1. Em geral, nas linhas sísmicas, a DEmb foi mapeada pela diferença dos padrões de sismofácies de caótico para planoparalelo do intervalo pré-rifte (Figura 9). Os atributos sísmicos pseudo-relief e amplitude instantânea auxiliaram muito na identificação desse limite, acentuando as diferenças de impedância acústica dessas unidades. O limite superior (DR1 ou DR2) foi bem marcado por terminações principalmente do tipo onlap da unidade sobreposta

Com uma espessura sísmica aproximadamente constante, em geral essa sequência apresentou espessura sísmica em torno de $250 \mathrm{~ms}$ (milissegundos). De maneira dispersa, na porção leste da bacia, ocorre um leve espessamento da unidade, percebido pelo mapa de isópacas da mesma (Figura 10). Internamente, essa unidade sísmica apresenta boa continuidade, um padrão geral de refletores paralelos e com reflexão sísmica pouco nítida. 


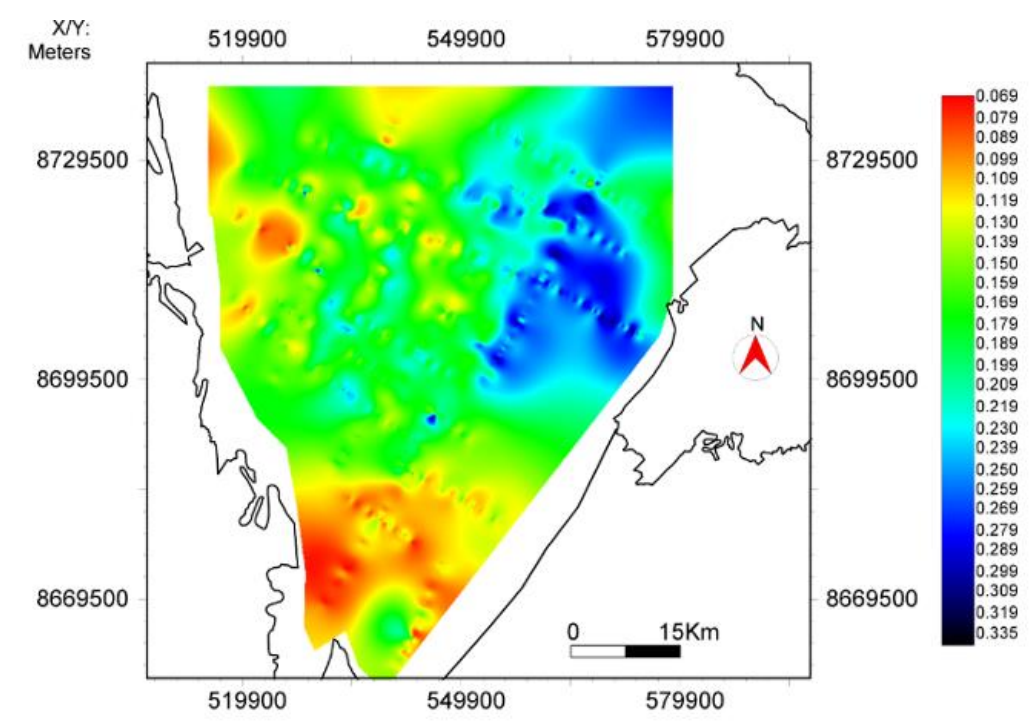

Figura 10 - Mapa de espessura sísmica da unidade Pré-rifte indicando espessamento da unidade para leste.

Em verdade, segundo os dados de poços, essa unidade sísmica está relacionada aos depósitos permianos da fase sinéclise e aos depósitos da fase pré-rifte relacionados às formações Aliança e Sergi, todos reunidos na unidade sísmica genérica Pré-rifte. Além disso, a sequência sísmica seguinte (Rifte 1), litoestratigraficamente relacionada às formações Itaparica e Água Grande, devido a sua pequena espessura em Tucano Sul, muitas vezes menor que 100 metros, não apresentou resolução para ser mapeada em sísmica, estando sismicamente inserida nessa unidade Pré-rifte. Sua definição foi feita através dos dados de poços e, conceitualmente, ela já compõe os estratos relacionados ao estágio rifte propriamente dito, segundo o modelo aqui adotado.

Segundo Costa et al. (2007), os registros do Cretáceo Inferior (formações Itaparica e Água Grande) possuem distribuição restrita, estando vinculados quase que exclusivamente à porção sudeste de Tucano Sul, apesar de terem evidências de sua ocorrência na porção norte também.

O poço 13, por exemplo, localizado na região oeste, não apresentou a ocorrência da sequência Rifte 1, colocando a Rifte 2 em contato direto com a unidade Pré-rifte (Figura 11).

Dessa forma, mesmo nos locais em que se preservou a sequência Rifte 1, a superfície DR1 encontra-se fundida sismicamente com a discordância DR2, devido à pouca resolução sísmica para imagear os refletores da Rifte 1.

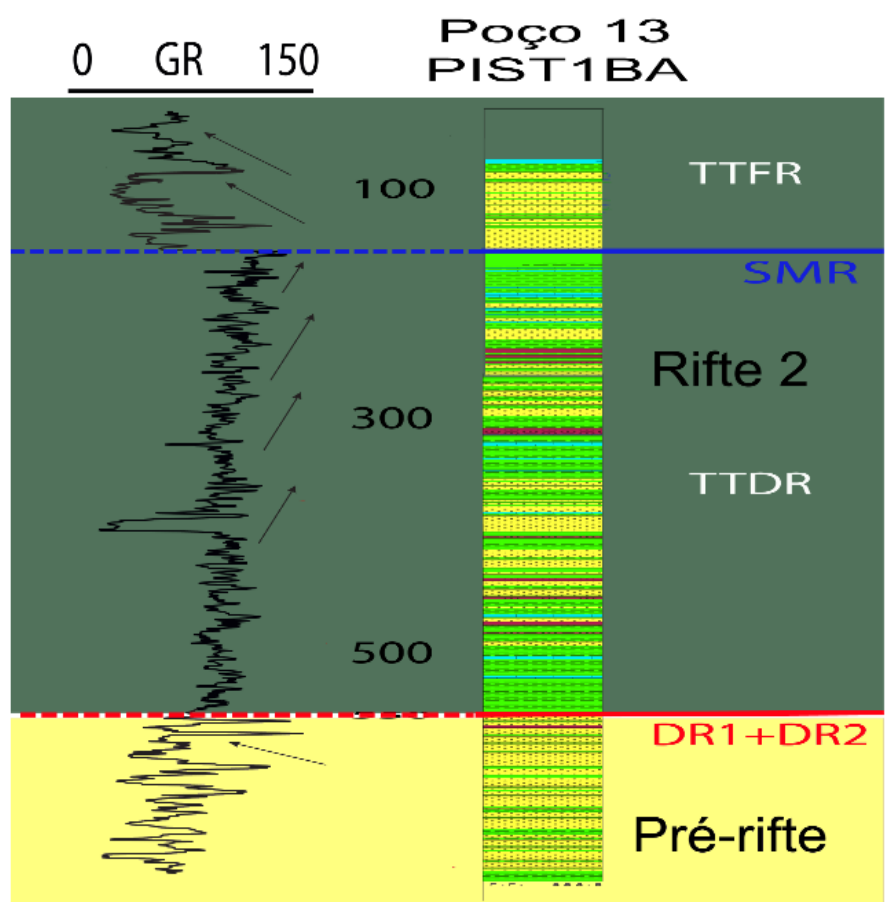

Figura 11 - Interpretação do poço 13 (PIST 1 BA) localizado na região sudoeste da bacia de Tucano Sul, o qual não apresentou a ocorrência de depósitos da sequência Rifte 1, colocando Rifte 2 em contato direto com o embasamento. 


\section{Fase Rifte}

O mapeamento sismoestratigráfico dessa região identificou 3 sequências ao longo da supersequência rifte a partir da identificação de suas respectivas discordâncias em sísmica, e com o auxílio dos dados de poços, em especial o perfil de Gama Ray e o perfil litológico construído a partir de amostras de calha.

O nível de detalhe trazido com a interpretação dos dados de poços agregou maior confiabilidade na interpretação em sísmica das superfícies estratigráficas do modelo. A seção interpretada na figura 12 mostra que foram definidas então as sequências Rifte 1, Rifte 2 e Rifte 3 na área de estudos. Como será abordado adiante, a sequência Rifte 1 foi interpretada apenas nos dados de poços, não tendo resolução para ser vista em sísmica.

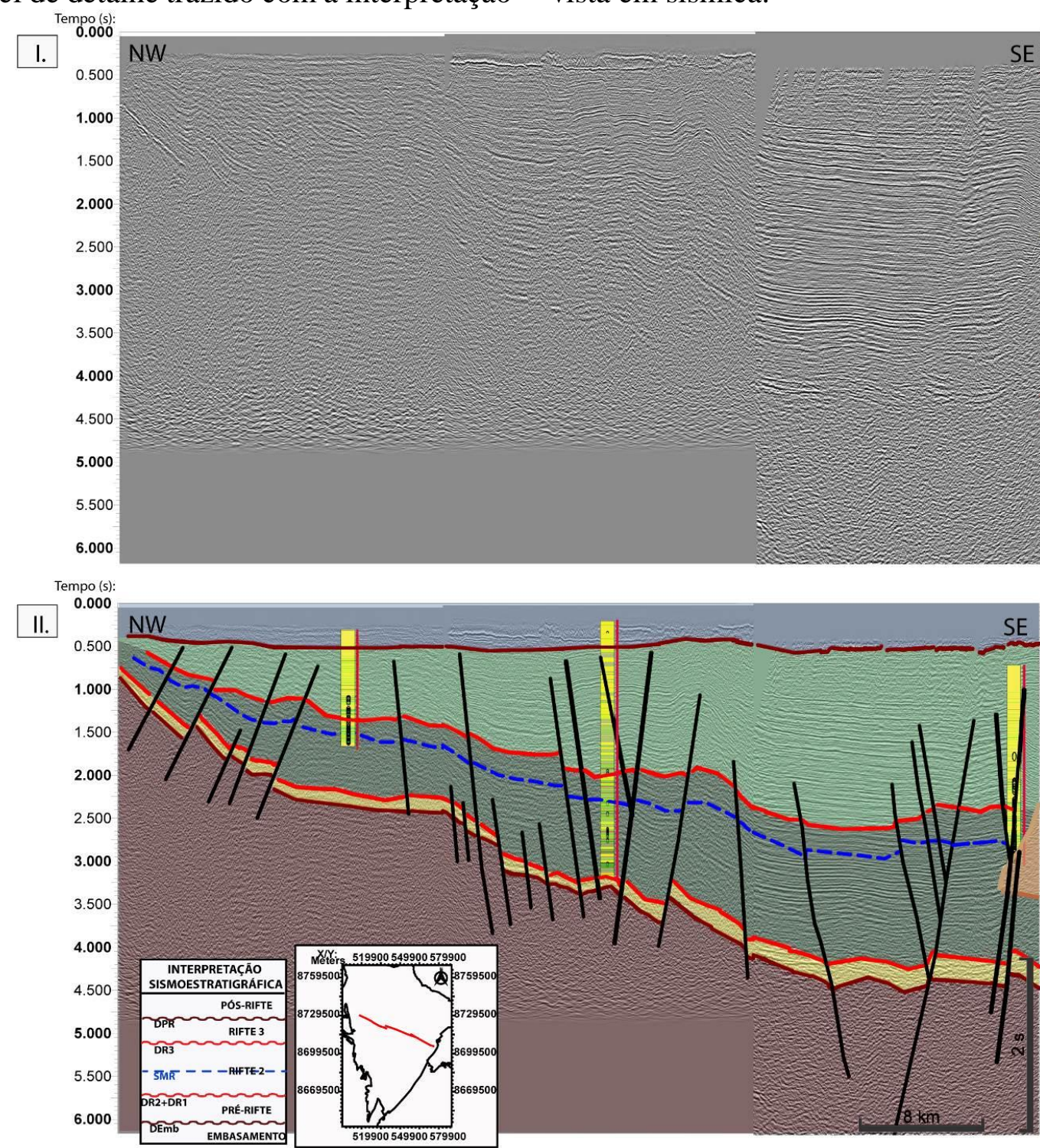

Figura 12 - Seção sísmica composta dip: (I.) não interpretada; (II.) com as unidades sismoestratigráficas interpretadas. Em sísmica foi possível mapear apenas duas sequências rifte (Rifte 2 e Rifte 3), bem como as unidades Pré-rifte e Pósrifte.

Próximo à borda falhada, várias linhas sísmicas mostraram a ocorrência de refletores sísmicos descontínuos com padrão inclinado e geometria externa em forma de cunha, conforme será visto no tópico de sismofácies.

Este padrão ocorre ao longo do intervalo rifte e deve estar associado aos conglomerados típicos de falha de borda. No arcabouço sísmico ele começa a ser identificado do meio para o final da sequência Rifte 2 e na sequência Pós-rifte ele não ocorre mais.

\section{Sequência Rifte 1}

A sequência sísmica Rifte 1 foi definida sobre a unidade Pré-rifte, limitada na base pela DR1 e no topo pela DR2.

Reunindo os depósitos das formações Itaparica e Água Grande, seu limite superior é bem marcado por terminações principalmente do tipo onlap da unidade sobreposta (Rifte 2), e foi identificado em vários poços que alcançam o 
intervalo. Contudo, seu limite inferior não apresentou acuidade sísmica para ser visto nas imagens, podendo ser identificado apenas nos dados de poços.

No poço 3 (Figura ), é possível perceber uma mudança no padrão de raios gama de uma tendência progradacional/agradacional, próprio do contexto de formação da sequência Rifte 1, com tímida criação de espaço que marca o começo do processo de rifteamento, para o contexto deposicional da sequência seguinte (Rifte 2 - TTDR), com tendência cada vez mais retrogradacional e criação de espaço crescente.

A espessura sísmica média dessa sequência não pôde ser definida. Da mesma forma, não foi possível identificar com segurança um padrão típico de refletores devido à insuficiente acuidade sísmica.

Ainda assim, possivelmente, o espessamento para sudeste atribuído à sequência sísmica anterior deve estar associado à ocorrência e preservação dessa sequência Rifte 1 . Segundo a bibliografia (e.g. Wiederkehr, 2010), as formações Itaparica e Água Grande já marcam a influência do estágio inicial de subsidência do rifte, com mudanças nos sentidos das paleocorrentes em tais depósitos e espessamento nos depocentros

POÇO 3

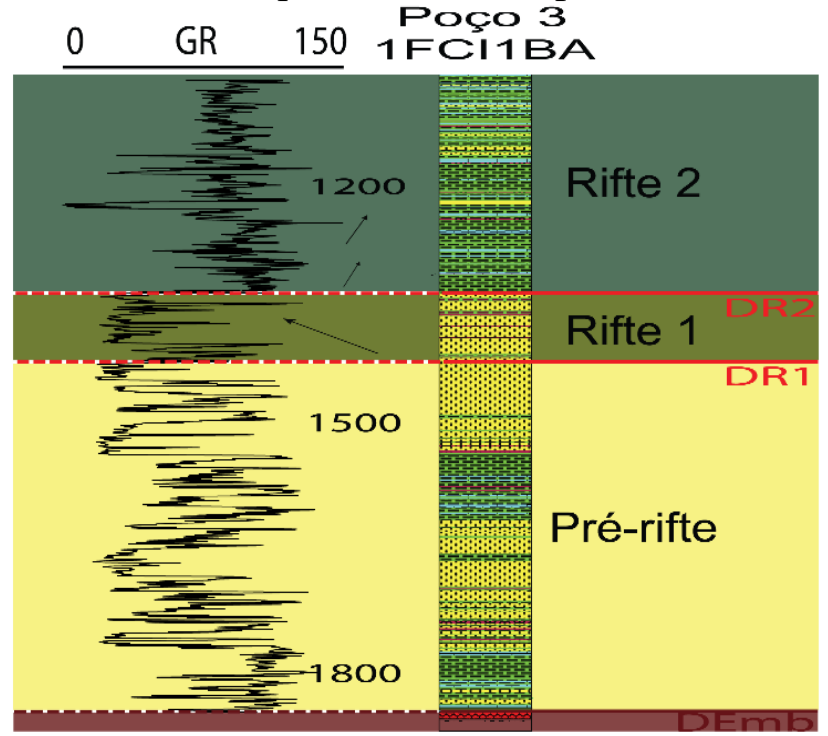

Figura 13 - Interpretação do poço 3 (1FCI 1 BA) localizado na região sudoeste da bacia de Tucano Sul. Destaque dado (setas pretas) para a mudança no padrão de raios gama de uma tendência progradacional em Rifte 1 para retrogradacional em Rifte 2.

Esta sequência sísmica é a que apresenta a menor expressividade em termos de espessura na área de estudo. Ela teria sido formada durante os primeiros pulsos tectônicos, em contexto de taxas de extensão ainda relativamente baixas, com falhas de pequenos rejeitos e pouca criação de espaço. É composta pelo Trato Tectônico de Início de Rifte, caracterizado pelo contexto de progradação de sistemas flúvio-eólicos e lacustres restritos.

\section{Sequência Rifte 2}

A sequência Rifte 2 é limitada na base pela discordância rifte 2 (DR2 ou discordância de início de desenvolvimento de rifte - DIDR) e no topo pela discordância rifte 3 (DR3). Em sísmica, a DR2 foi marcada por onlap basais principalmente. A DR3 foi mapeada a partir de alguns truncamentos erosivos e onlaps sobrepostos interpretados nas seções sísmica, e teve o auxílio dos padrões de sismofácies presentes nas unidades em questão.
Internamente, ela se caracteriza por um padrão de refletores geralmente contínuos, paralelos a subparalelos, melhor marcados mais próximo ao depocentro da bacia, e também por refletores apagados ou "borrados". A espessura sísmica dessa unidade varia muito ao longo da bacia, de $250 \mathrm{~ms}$ na margem flexural até $1200 \mathrm{~ms}$ (até aproximadamente 2400 metros) junto à borda falhada (Figura 14). Essa é uma característica importante dessa unidade, que apresenta espessamento marcante em direção às falhas principais, com um padrão divergente bem acentuado, associado a seu estágio tectônico de formação - pleno desenvolvimento do rifte.

Conforme indicado em vários poços, essa unidade reúne depósitos relacionados às formações Candeias e Marfim. Internamente à Rifte 2, uma superfície de downlaps mergulhando geralmente para sudeste foi identificada em algumas seções sísmicas dip nesta unidade. Essa superfície de downlaps foi 
interpretada como a superfície de máximo rifteamento (SMR2) da Rifte 2, indicando o momento de passagem do estágio de máxima criação de espaço nessa sequência, com retrogradação do sistema lacustre, para o estágio seguinte de menor criação de espaço, com progradação dos deltas para dentro do lago. Essa superfície de máximo rifteamento segmenta a sequência Rifte 2 nos tratos tectônicos de desenvolvimento (TTDR) e final de rifte (TTFR).

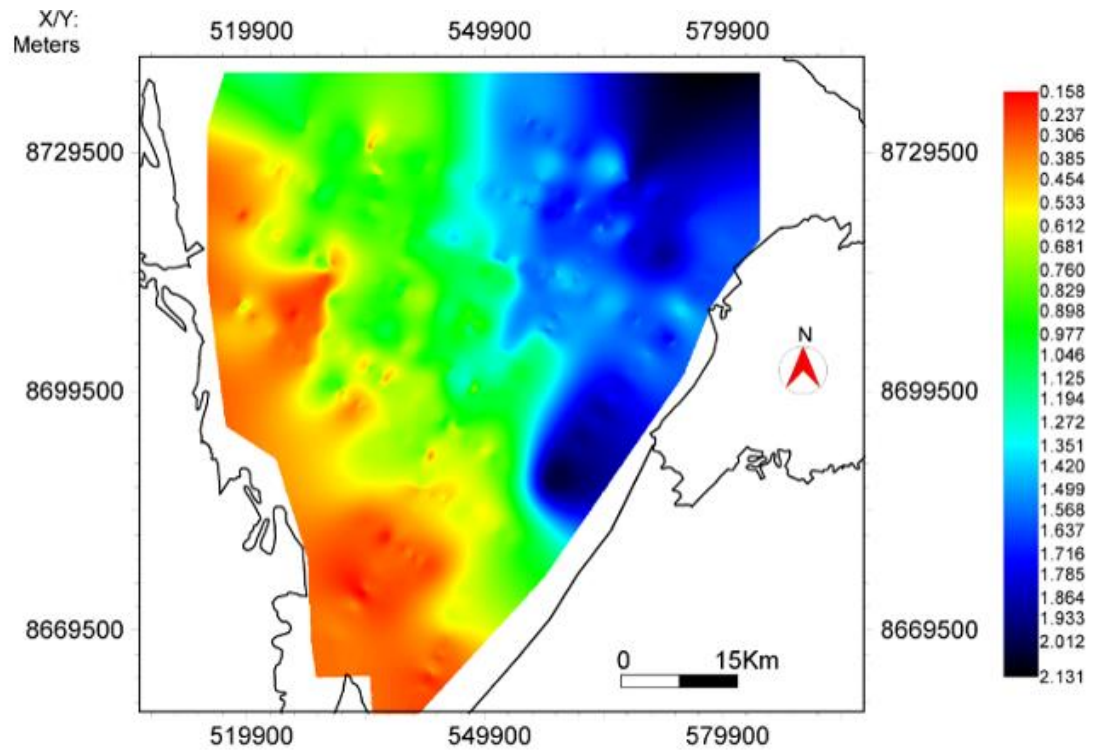

Figura 14 - Mapa de espessura sísmica da sequência Rifte 2 indicando espessamento da unidade para nordeste.

A análise dos poços auxiliou, em algumas regiões, o posicionamento da SMR2 a partir da análise dos padrões de raios gama. Apesar de ser apenas uma estimativa, ela foi útil nas regiões onde os downlaps encontrados em sísmica não eram evidentes em razão das baixas amplitudes e resoluções sísmicas. No poço 8, por exemplo, foi possível interpretar o TTDR e TTFR da sequência Rifte 2, a partir do posicionamento da
SMR2 segundo o padrão de RG (Figura 15). As curvas de raios gama tem inicialmente padrões agradacionais seguidos por padrões cada vez mais retrogradacionais que marcam o estágio de muita criação de espaço. Essa tendência muda para regimes cada vez mais progradacionais com o amadurecimento do pulso tectônico. $\mathrm{Na}$ passagem de um regime para o outro se forma uma SMR.

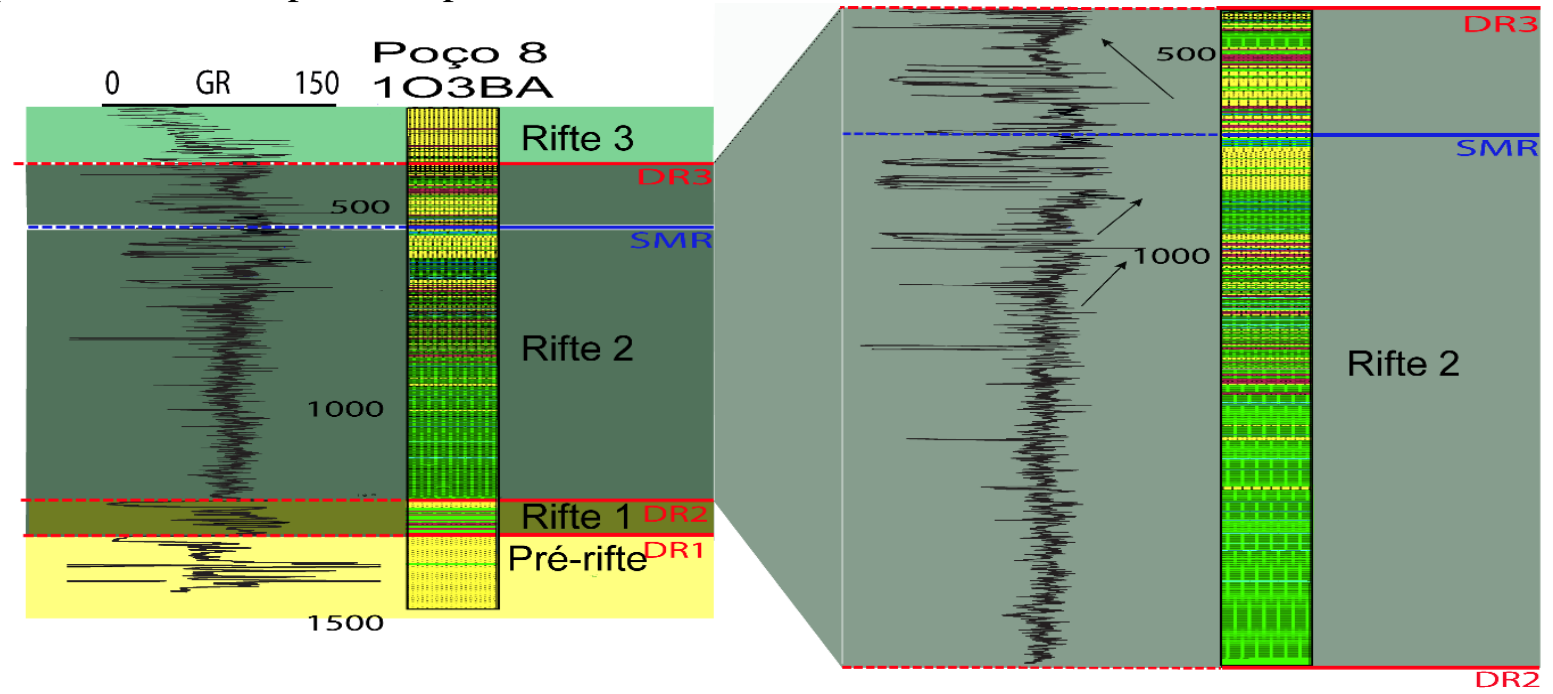

Figura 15 - Interpretação do poço 8 (1 O3 BA) localizado na região sul da bacia de Tucano Sul. Destaque para a sequência Rifte 2 que registra uma mudança no regime deposicional de retrogradação (TTDR) para progradação (TTFR) marcando a superfície de máximo rifteamento (SMR).

\section{Sequência Rifte 3}

Sobreposta à Rifte 2, a sequência Rifte 3 é limitada na base pela discordância rifte 3 (DR3) e no topo pela discordância pós-rifte (DPR). A DR3 foi mapeada principalmente por onlaps e downlaps basais e alguns truncamentos, mais 
comuns próximos à margem flexural da bacia. Já a DPR foi identificada a partir do mapeamento de truncamentos evidentes, onde é possível ver a diferença angular entre os refletores inclinados do final da seção rifte truncados pelos refletores horizontalizados da fase subsequente Pós-rifte. Com relação ao padrão interno dos refletores, a sequência Rifte 3 se caracteriza por um padrão de refletores eminentemente contínuos, paralelos a sub-paralelos, bem marcados e com amplitude e frequência características. De maneira subordinada, ocorre também o padrão sísmico de refletores sem reflexão, ou com reflexões apagadas. Conforme a figura 16, a espessura sísmica dessa sequência também é variável ao longo da bacia. Na borda flexural, a oeste da bacia, ela é mais fina, medindo até $150 \mathrm{~ms}$ em alguns pontos. E na borda falhada sua espessura pode alcançar até $1500 \mathrm{~ms}$ (aproximadamente 3000 metros).

Segundo os dados de poços, essa sequência sísmica reúne depósitos do estágio final do rifteamento, associados principalmente às formações litoestratigráficas Pojuca e São Sebastião.

Em poço, nota-se uma evidência de diminuição da argilosidade das rochas em direção ao topo (Figura 17). Contudo, em sísmica não foi possível identificar com clareza sucessivos downlaps que pudessem indicar a posição da superfície de máximo rifteamento da sequência Rifte 3.

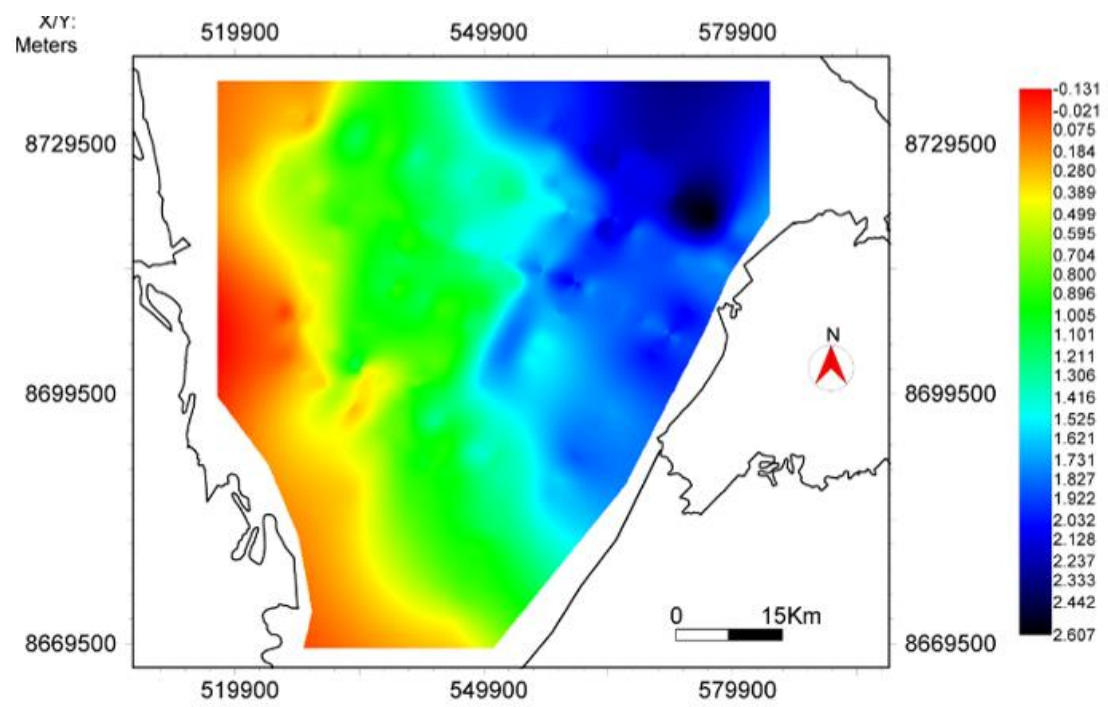

Figura 16 - Mapa de espessura sísmica da sequência Rifte 3 indicando espessamento da unidade para nordeste.

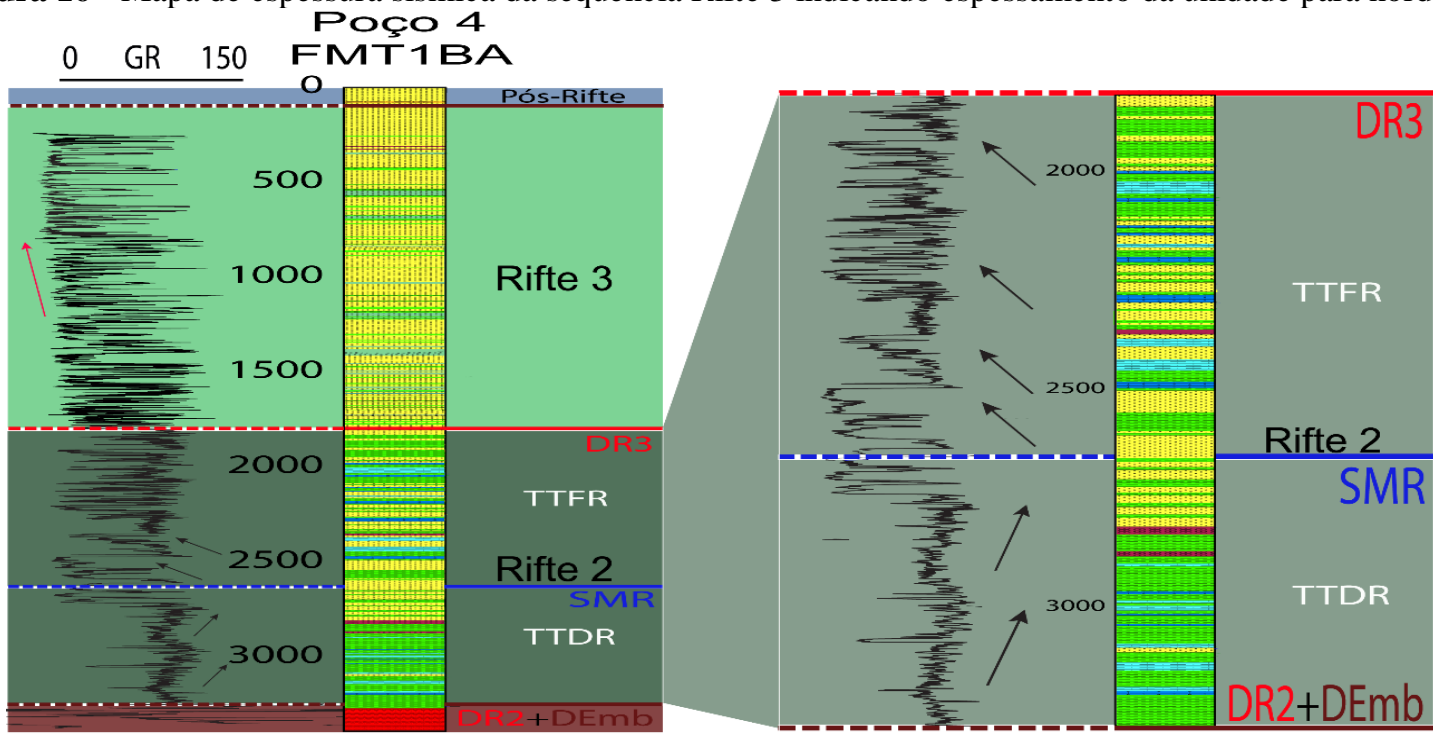

Figura 17 - Interpretação do poço 4 (1 FMT 1 BA) localizado na região sudeste da bacia de Tucano Sul. Na sequência Rifte 3, a seta em vermelho indica diminuição da argilosidade para o topo no perfil Gama Ray. A sequência Rifte 2 registra a superfície de máximo rifteamento, marcada pela passagem do regime retrogradacional (TTDR) para progradacional (TTFR).

Além disso, internamente a essa sequência, é mudança importante no padrão de refletores. Na possível ver em algumas linhas sísmicas uma base prevalecem refletores bem marcados pelo 
maior contraste de impedância acústica entre eles e no topo os refletores estão pouco nítidos. Esse fato deve estar associado ao ambiente deposicional de formação desses dois intervalos. $\mathrm{Na}$ base são os depósitos deltaicos/lacustres da formação Pojuca com intercalação de folhelhos e arenitos - do pró-delta/planície lacustre e da frente deltaica, respectivamente - com maior contraste de impedância acústica. No topo prevalecem os arenitos flúvio-eólicos da formação São Sebastião, com um ciclo mais monótono de impedância das rochas.

\section{Fase Pós-Rifte}

Por fim, foi definida a base da unidade Pósrifte, marcada pelos onlaps discordantes do estágio Pós-rifte, depositados na flexura termal pós-rifteamento. A caracterização do seu padrão de refletores foi dificultada na maioria das linhas sísmicas estudadas por conta da cobertura das linhas que cobrem muitas vezes apenas suas porções mais basais. Contudo, em geral, são refletores plano-paralelos claramente horizontalizados.

\section{Sismofácies}

De acordo com a figura 18, foram caracterizadas e definidas cinco sismofácies, denominadas SF1 à SF5. Mais uma vez, a orientação da linha sísmica em relação à deposição de sedimentos foi crucial na definição das fácies sísmicas, sendo mais fácil identificálas no sentido da deposição (dip) do que em sentido perpendicular.

A sismofácies SF1 apresenta uma configuração de refletores paralela a subparalela, predominantemente contínua, frequência baixa e amplitude geralmente baixa. Esta sismofácies ocorre em vários setores da área de estudo, mas considerando todas as características dos seus refletores como o espaçamento entre eles, angularidade, nota-se que na sequência Pré-rifte, depositada em contato com o embasamento, ocorre bastante essa sismofácies. Essa fácies sísmica foi interpretada como intercalação de arenitos flúvio-eólicos e folhelhos lacustres, interpretação corroborada pelo Poço 1 que cruza a linha sísmica 14, o qual alcança o embasamento, passando antes pelo intervalo pré-rifte.

A sismofácies SF2 é caracterizada por um padrão de refletores com configuração paralela a subparalela, com continuidade que varia de descontínua a contínua, predominando a contínua, com amplitude e frequência altas. Sua ocorrência foi associada a presença de folhelhos de lago profundo com lentes de arenitos de fluxos gravitacionais. Sua distribuição nas linhas sísmicas está especialmente associada aos depocentros da bacia, sendo reconhecida principalmente na sequência Rifte 2 . Além disso, foi possível correlacionar essa fácies sísmica às informações contidas no perfil litológico de alguns poços, como o poço 10 , que alcança o depocentro da bacia, pegando parte dessa sismofácies.

A sismofácies SF3 tem uma configuração de refletores eminentemente contínuos (perdendo continuidade em zonas falhadas e fraturadas), paralelos, com geometria tabular, frequência baixa e amplitude alta. Com o auxílio dos dados de alguns poços (Poço 5, por exemplo) que cortam essa fácies sísmica, ela foi interpretada como uma intercalação de arenitos e folhelhos flúvio-deltaicos-lacustres. É importante frisar que essa sismofácies foi reconhecida - na sequência Rifte 3 , e de maneira subordinada no topo da sequência Rifte 2 .

Na sismofácies SF4, o padrão dos refletores é a total ausência de padrão entre eles, com geometria caótica, ausência de continuidade e frequência e amplitudes baixas. Essa sismofácies foi associada ao embasamento cristalino da bacia. Foi possível correlacionar essa sismofácies com dados indiretos de rocha obtidos no perfil composto do Poço 10 que alcança o embasamento.

É preciso sinalizar para um fato importante: eventualmente na sismofácies SF4 é possível ver o que parecem ser refletores mais ou menos planos, indicando suposto acamadamento de estratos. Além disso, em alguns pontos da bacia, foram identificadas regiões com refletores planoparalelos bem marcados e mesmo assim associados ao embasamento. Esse fato foi atribuído à existência de rochas metavulcanosedimentares do greenstone belt do Rio Itapicuru, metassedimentos da cobertura cratônica Estância ou rochas sedimentares da Bacia Palmares, todas componentes do embasamento da bacia de Tucano Sul (SILVA et al., 2007) e que podem ter refletido um eventual acamadamento visto na sísmica.

A sismofácies SF5 tem uma configuração de refletores característica, com geometria em formato de cunha, com refletores com frequência e amplitude alternando entre baixa e alta, com pouca ou nenhuma continuidade e com certa inclinação em relação à horizontal. Sua distribuição é restrita às linhas sísmicas que cortam a falha principal da bacia na região 
nordeste. Certamente esse fato culminou na

conglomerados formados em ambientes de interpretação dada a essa sismofácies: ela foi leques aluviais, típicos da falha de borda de relacionada à ocorrência de arenitos e bacias rifte.

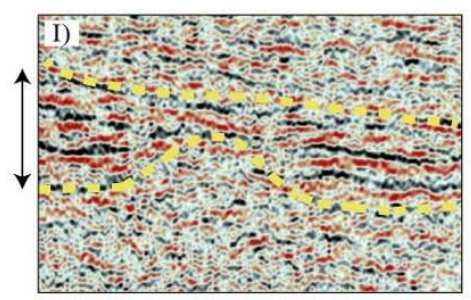

\begin{tabular}{|c|c|c|}
\hline Frequência & baixa & \multirow{4}{*}{$\begin{array}{l}\text { Sismofácies } \\
\text { interpretada } \\
\text { como } \\
\text { intercalação de } \\
\text { arenitos flúvio- } \\
\text { eólicos e folhe- } \\
\text { lhos lacustres. }\end{array}$} \\
\hline Amplitude & baixa & \\
\hline Continuidade & $\begin{array}{l}\text { Predominantemente } \\
\text { contínua mas } \\
\text { descontínua em } \\
\text { partes }\end{array}$ & \\
\hline Geometria & $\begin{array}{l}\text { Paralela a sub- } \\
\text { paralela }\end{array}$ & \\
\hline
\end{tabular}

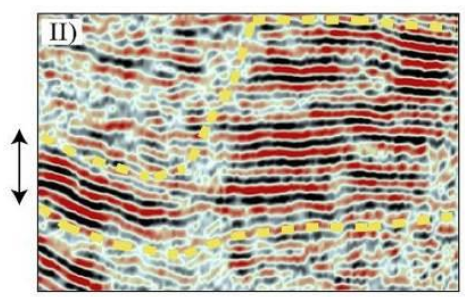

\begin{tabular}{|l|l|l|}
\hline Frequência & alta & $\begin{array}{l}\text { Sismofácies } \\
\text { interpretada } \\
\text { como depósitos } \\
\text { de folhelhos de } \\
\text { lago profundo } \\
\text { com lentes de } \\
\text { arenitos de } \\
\text { fluxos gravita- } \\
\text { cionais. }\end{array}$ \\
\hline Geometria & alta & $\begin{array}{l}\text { Descontínua / } \\
\text { ligeiramente contín }\end{array}$ \\
\hline
\end{tabular}

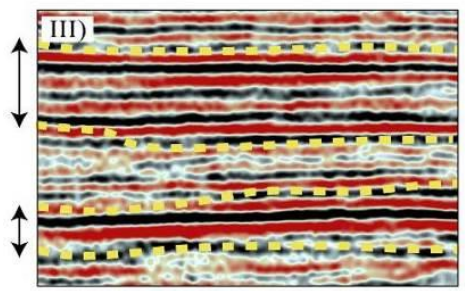

\begin{tabular}{|c|c|c|}
\hline Frequência & baixa & \multirow{4}{*}{$\begin{array}{l}\text { Sismofácies } \\
\text { interpretada } \\
\text { como intercala- } \\
\text { ção de arenitos } \\
\text { folhelhos flúvio- } \\
\text { deltaicos-lacus- } \\
\text { tres. }\end{array}$} \\
\hline Amplitude & alta & \\
\hline Continuidade & $\begin{array}{l}\text { Eminentemente } \\
\text { contínua }\end{array}$ & \\
\hline Geometria & Paralela & \\
\hline
\end{tabular}

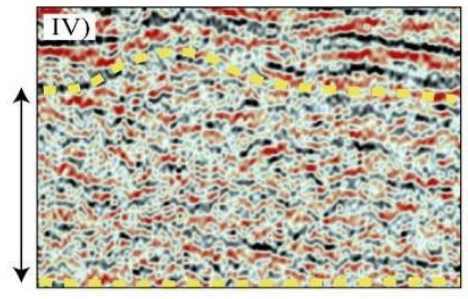

\begin{tabular}{|l|l|l|}
\hline Frequência & baixa & $\begin{array}{l}\text { Sismofácies } \\
\text { associada ao em- } \\
\text { basamento, com- } \\
\text { posto por ortog- } \\
\text { naisses migmatíti- } \\
\text { cos, rxs meta- } \\
\text { vulcano-sedimen- } \\
\text { tares e rxs me- } \\
\text { tassedimentares. }\end{array}$ \\
\hline Geometria & baixa & Ausente \\
\hline
\end{tabular}

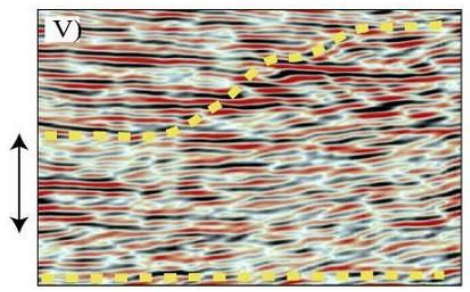

\begin{tabular}{|l|l|l|}
\hline Frequência & baixa e alta & $\begin{array}{l}\text { Sismofácies } \\
\text { interpretada } \\
\text { como arenitos e } \\
\text { conglomerados } \\
\text { típicos de am- } \\
\text { bientes de leques } \\
\text { aluviais identifica- } \\
\text { dos próximo à } \\
\text { falha principal. }\end{array}$ \\
\hline Geometinuidade & $\begin{array}{l}\text { Descontínua } \\
\text { principalmente }\end{array}$ & Em cunha \\
\hline
\end{tabular}

Figura 18 - Principais sismofácies identificadas nas linhas sísmicas. I) Sismofácies SF1. II) Sismofácies SF2. III) Sismofácies SF3. IV) Sismofácies SF4. V) Sismofácies SF5.

Nas figuras 19 e 20, as seções compostas interpretadas permitem estimar a distribuição das cinco sismofácies caracterizadas na área de estudos.

\section{Discussões}

Com o arcabouço estratigráfico de Tucano Sul analisado foi possível estabelecer um paralelo com a bacia de Recôncavo.

Com relação à quantidade de sequências sismoestratigráficas interpretadas em ambas bacias, na bacia do Recôncavo, Vilas Boas (2016) identificou quarto sequências sin-rifte (Figura 21). Vale ressaltar que ele estudou a parte centro-sul dessa bacia e, obviamente, em algumas seções ele não identificou todas as quatro sequências preservadas.

Em Tucano Sul foram identificadas três sequências para esse mesmo intervalo. Apesar de serem bacias distintas com evoluções diacrônicas individuais, é interessante perceber que duas bacias irmãs, coetâneas, vizinhas, formadas em um mesmo evento tectônico, tenham um arcabouço e uma assinatura estratigráfica tão distintas.

Conforme visto em dados de poços e na bibliografia, Tucano Sul teve um assoreamento muito mais rápido do que o Recôncavo. No Recôncavo, após a formação do Lago Candeias, a criação de espaço subsequente foi tal que a espessura de lâmina d'água gerada possibilitou a formação do lago Maracangalha na sequência Rifte 3 do Recôncavo (Figura 21). Em Tucano Sul não ficou preservada a sequência que teria os depósitos do "lago" Maracangalha. 


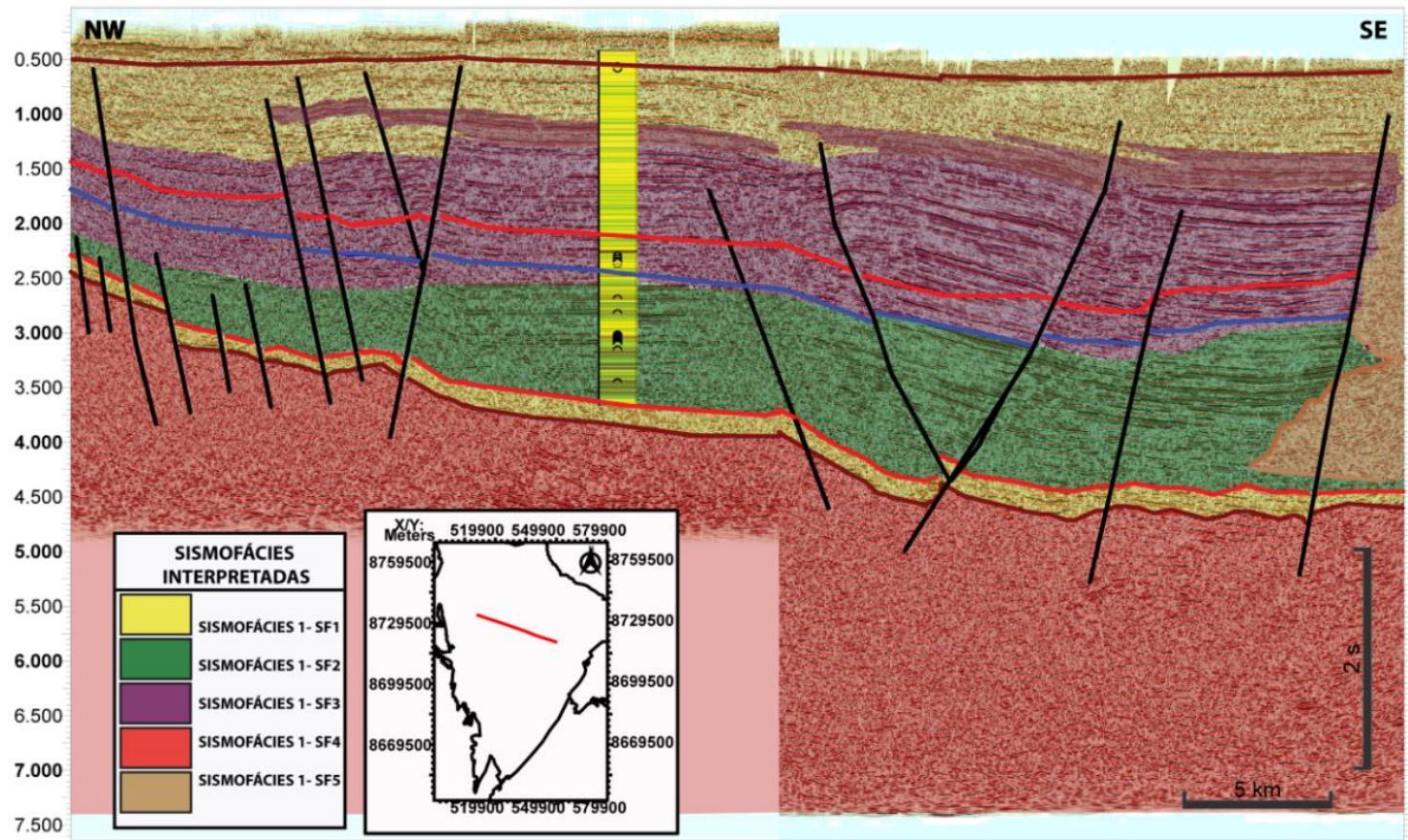

Figura 19 - Seção composta orientada no trend deposicional (NW-SE) com sismofácies interpretadas.

A sequência Rifte 3 de Tucano Sul tem na sua base a discordância DR3. Esta superfície é reconhecida não apenas no rifte RecôncavoTucano-Jatobá, mas também na margem continental entre as bacias do Espírito Santo e Sergipe-Alagoas (Bueno, 2004). No Recôncavo ela marca a base da sequência Rifte 4 . Ela teria sido formada no evento tectônico de breakup, há $134 \mathrm{Ma}$ aproximadamente. Esse evento marcou o 0.000

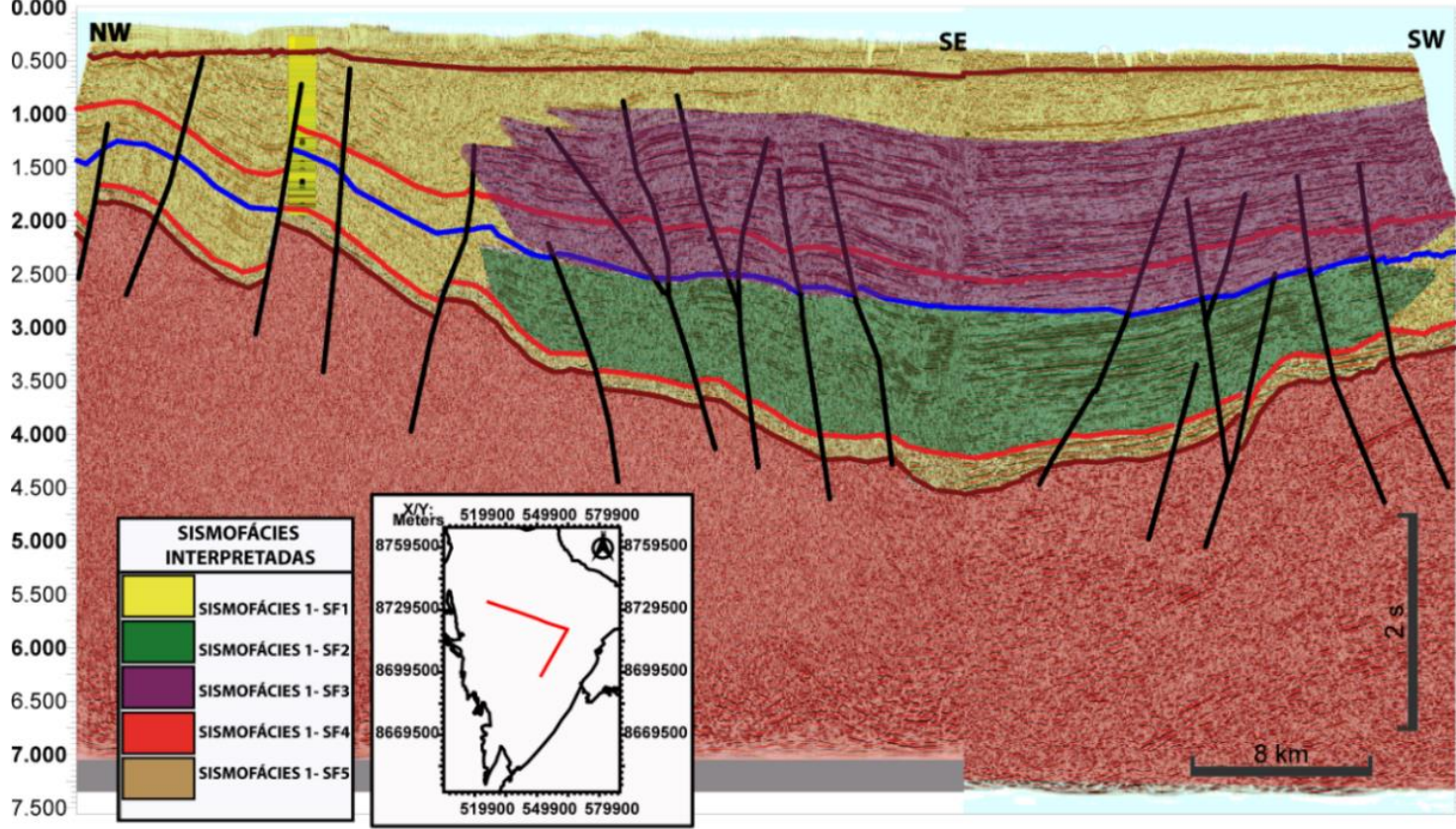

Figura 20 - Seção composta orientada NW-SE-SW com sismofácies interpretadas.

Comparando o empilhamento litoestrati- de ruptura da crosta, apresenta maior divergência gráfico da seção rifte de ambas as bacias, vê-se que a bacia do Recôncavo tem mais discordâncias, mais interrupções no seu empilhamento. Ela está mais próxima do centro encerramento da fase rifte mais a sul, no segmento entre o norte da Bacia de Pelotas e o sul da Bacia de Santos, bem como a propagação para norte do sistema de riftes da margem leste. Assim, foi um evento de magnitude regional que teria provocado a omissão desse intervalo em Tucano, bem como de seções correlatas nas bacias do Espírito Santo, Cumuruxatiba, Almada, Camamu e Sergipe-Alagoas. 


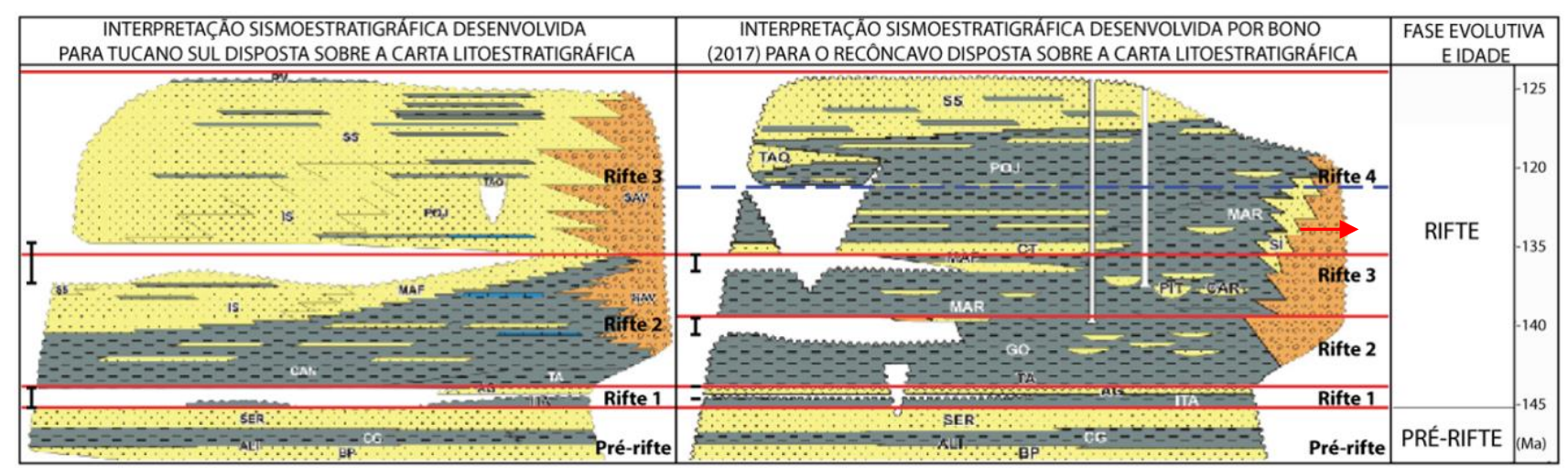

Figura 21 - Diagrama relacionando a interpretação estratigráfica aqui desenvolvida para Tucano Sul com a desenvolvida por Vilas Boas (2016) para a bacia do Recôncavo sobre a sucessão litoestratigráfica proposta por Costa et al. (2007) e Silva (2007) respectivamente.

A figura 22 mostra um esquema simplificado construído para representar como pode ter acontecido esse evento que omitiu os depósitos da formação Maracangalha em Tucano e em outras bacias da marguem continental brasileira. O evento de breakup foi relacionado por Bueno (2004) ao tectonismo que promoveu contemporaneamente a implantação de crosta oceânica no segmento compreendido entre as bacias de Santos e Pelotas. A esta época aproximadamente, a margem flexural do rifte Recôncavo-Tucano Jatobá começava a adquirir estabilidade tectônica, marcando o encerramento da fase de expansão dessas bacias em função do deslocamento para leste, dos esforços relacionados à abertura do Atlântico Sul (Bueno, 2004).

Segundo Bueno (2004), a implantação de crosta oceânica à sul provocou parada na subsidência mecânica, soerguimento na plataforma continental brasileira em 134 milhões de anos (Figura 23), descida do nível de base e exposição à erosão de grandes áreas continentais, resultando nessa importante erosão em Tucano e em bacias adjacentes.

Sobre o modelo estratigráfico de sequências adotado para caracterizar Tucano Sul, levantou-se uma questão sobre onde posicionar a SMR da sequência Rifte 3, não identificada na sísmica. Sendo a Rifte 3 uma sequência eminentemente arenosa surge a dificuldade de identificar uma mudança de regime deposicional preconizada pelo modelo. Além disso, essa ausência de uma seção pelítica clássica na base da sequência marcando o TTDR não vai de encontro com o modelo utilizado. Como o próprio nome já diz, trata-se de um modelo apenas, um plano norteador de como interpretar o empilhamento sedimentar de um rifte, e não uma fórmula exata de como descrever as coisas.
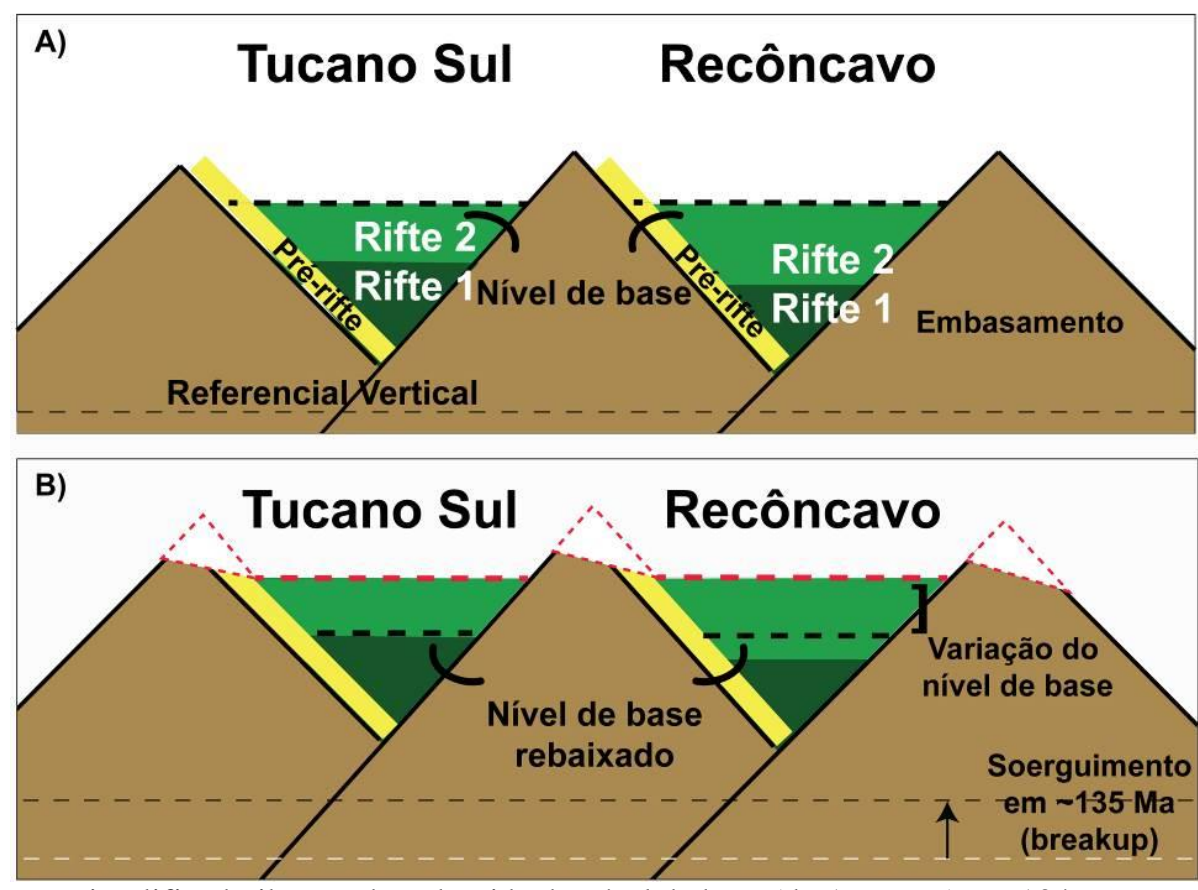

Figura 22 - Esquema simplificado ilustrando a descida do nível de base (de A para B) em 134 Ma, que promoveu erosão significativa em Tucano Sul e Recôncavo. 


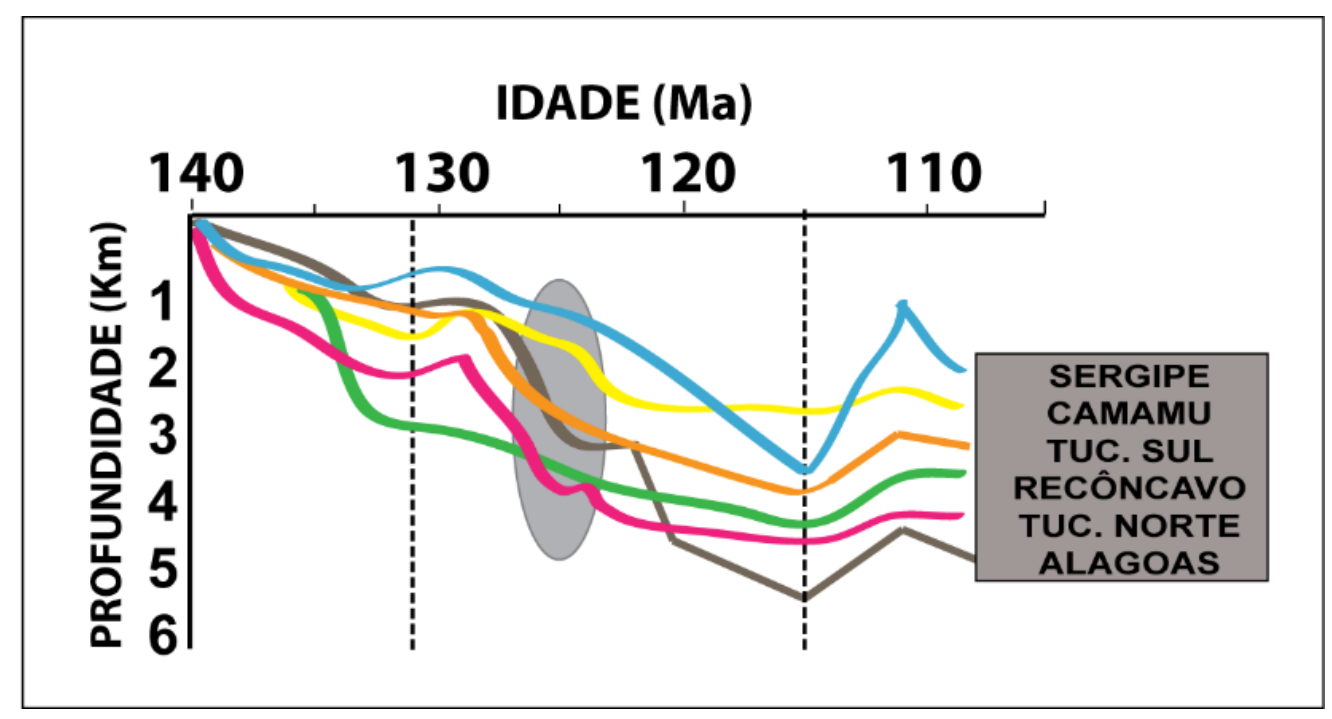

Figura 23 - Curvas de subsidência de algumas bacias sedimentares do nordeste. Destaque dado ao evento de $134 \mathrm{Ma}$ marcando o soerguimento resultante do evento de breakup. Modificado de Bueno (2004).

Pode até ser que esse modelo não explique satisfatoriamente a evolução tectono-sedimentar de Tucano Sul. Mas o fato de não ser possível identificar a SMR3 em sísmica não significa que ela não esteja lá necessariamente. Na base da Rifte 3 são registrados ciclos flúvio-deltaicos-lacustres, então existia muito espaço disponível para acomodar.

Acima, ocorrem ciclos flúvio-eólico indicando uma tendência cada vez mais progradacional para o topo. O equivalente distal dos deltas mais arenosos basais da Rifte 3 no Recôncavo são pelitos de lagos mais profundos e do pró-delta. $\mathrm{O}$ trend de sedimentação dessas bacias foi o mesmo, sendo Tucano Sul mais proximal, mais próximo da área fonte, e Recôncavo mais distal e mais profundo regionalmente, conforme indicado pelas seções geológicas de ambas as bacias (e.g. Costa et al. 2007, Silva et al. 2007).

Em verdade, os modelos em geral não conseguem representar exatamente como as coisas acontecem de fato na natureza. Eles levam em conta simplificações importantes, que não ocorrem na natureza, justamente para facilitar a aplicação e o entendimento. Na área de estudo, só a tectônica não poderia explicar a diferença na assinatura estratigráfica existente entre Tucano Sul e Recôncavo. É preciso considerar toda a interação existente no tripé tectônica, clima e aporte, que deve ter sido diferente em cada contexto.

\section{CONSIDERAÇÕES FINAIS}

O arcabouço sismoestratigráfico de Tucano Sul foi caracterizado pela formação e preservação de três sequências sismoestratigráficas de segunda ordem no intervalo rifte. A sequência Rifte 1 caracterizada apenas através dos dados dos poços, pois sua pouca espessura implicou numa baixa resolução sísmica. Ela é composta pelo Trato Tectônico de Início de Rifte que registra o estágio inicial de flexura da crosta, com pouca criação de espaço de acomodação e progradação de sistemas flúvio-lacustres.

A sequência Rifte 2 registra o estágio seguinte do rifteamento, com criação crescente de espaço e expansão do sistema lacustre. Este é o Trato Tectônico de Desenvolvimento de Rifte. A sequência Rifte 2 é encerrada pelo Trato Tectônico de Final de Rifte que marca a progradação dos deltas para dentro do lago devido à diminuição na criação de espaço face à aquiescência tectônica. Essa passagem do TTDR para o TTFR é marcada pela SMR identificada em sísmica por downlaps sucessivos.

Na sequência Rifte 3, por sua vez, não foi possível caracterizar em sísmicas uma superfície nítida que indicasse uma mudança clara de regime deposicional dentro da sequência. Percebe-se nos dados de poços, contudo, uma diminuição da argilosidade para o topo do empilhamento representando uma tendência progradacional geral dos sistemas com depósitos flúvio-deltaicolacustres basais e flúvio-eólico para o topo. Esse ponto exaltou o fato de que todo modelo funciona como um norteador na explicação de uma realidade que é mais complexa e multifacetada.

Interna à sequência Rifte 3 identificou-se uma mudança de sismofácies perceptível, com refletores com alto contraste de impedâncias acústica na base para refletores apagados 
provavelmente associada ao ambiente de formação desses intervalos.

Abaixo da sequência Rifte 1 foi definida a unidade sísmica Pré-rifte composta pelos refletores associados à fase sinéclise e à seção jurássica que antecede a subsidência do rifte. Acima da sequência Rifte 3 restou definida a unidade sísmica Pós-Rifte que reúne o intervalo associado à flexura termal pós-rifte.

Quanto às sismofácies, foram definidas as sismofácies SF1 a SF5, cada qual com seus parâmetros de frequência, amplitude, geometria interna e externa, configuração de refletores característicos.

A sismoestratigrafia correlativa entre a bacia de Tucano Sul e a bacia do Recôncavo mostrou primeiramente uma diferença no arcabouço sismoestratigráfico de ambas. Tucano Sul com uma seção pelítica mais delgada, restrita aos estágios iniciais do rifteamento e Recôncavo com aspecto mais distal composta por uma seção pelítica espessa.

Em termos de modelo estratigráfico de sequências, a bacia do Recôncavo preservou quatro sequências sismoestratigráficas no estágio rifte, conforme identificado por Vilas Boas (2016). Seria uma sequência a mais do que em Tucano Sul, o que é natural, pois trata-se de duas bacias distintas com evoluções diacrônicas individuais.

O evento tectônico responsável pela exposição de grandes áreas em Tucano Sul, descida do nível de base e omissão de seções importantes na bacia teve expressão regional e é atribuído pelos estudiosos como o evento que marcou o encerramento da fase rifte no segmento entre as bacias de Santos e Pelotas.

\section{AGRADECIMENTOS}

Os autores agradecem a Agência Nacional do Petróleo (ANP - Rio de Janeiro) pelo fornecimento de dados geológicos, e ao CNPq (Conselho Nacional de Pesquisas) pela outorga de bolsa de mestrado para N.L.Gaspar Nonato e pelo apoio à pesquisa (PQ 304657 / 15-8) para M. Holz; bem como ao Grupo de Estratigrafia Teórica e Aplicada da UFBA pelo suporte técnico-científico e pelo apoio logístico e material no desenvolvimento desse trabalho de pesquisa.

\section{REFERÊNCIAS}

BUENO, G. V. Diacronismo de eventos no rifte Sul Atlântico. Boletim de Geociências da Petrobras, Rio de Janeiro, v. 12, n. 2, p. 203-229, 2004.

CATUNEANU, O. Principles of Sequence Stratigraphy Elsevier, 106 p, 2006.

COSTA, I P.; MILHOMEM, P.S.; BUENO, G.V.; Silva, H.S.R.L.; KOSIN, M.D. Sub-bacia de Tucano Sul e Central, Boletim de Geociências, v. 15, n. 2, p. 433-443, 2007.

EMERY, D. \& MYERS, K.J. Sequence Stratigraphy. Oxford: Blackwell Science, 297 p., 1996.

GAWTHORPE, R.L. \& LEEDER, M.R. Tectono-sedimentary evolution of active mextensional basins. Basin Research, v. 12, p. 195-218, 2000 .

HOLZ, M.; TROCCOLI, E.B.; VIEIRA, M. Sequence stratigraphy of continental rift basins ii: An example from the brazilian cretaceous recôncavo basin. In: STRATIGRAPHY \& TIMESCALES: ADVANCES IN SEQUENCE STRATIGRAPHY, 2013, Springer, p. 15-18, 2014.

HOLZ, M.; VILAS-BOAS, D.B.; TROCCOLI, E.B.; SANTANA, V.C.; VIDIGALSOUZA, P.A. Conceptual Models for Sequence Stratigraphy of Continental Rift Successions. In: STRATIGRAPHY \& TIMESCALES: ADVANCES IN SEQUENCE STRATIGRAPHY (Ed. MONTENARI, M.), Chapter 4, p. 119-186, 2017.

HOLZ, M.; VILAS-BOAS, D.B.; TROCCOLI, E.B.; VIDIGALSOUZA, P.A. In: EAGE Conference. Kopenhagen, 2018. Along-strike variability of the stratigraphic signature of the rift successions: examples from Brazilian rift basins. Extended Abstract...Kopenhagen.

LAMBIASE, J. J. A model for tectonic control of lacustrine stratigraphic sequences in continental rift basins. In: KATZ, B. J. (Ed.). Lacustrine basin exploration: case studies and modern analogs. Tulsa: The American Association of Petroleum Geologists, (AAPG. Special Publication, 50), p. 265- 276, 1990.
MAGNAVITA, L.P.; DESTRO, N.; CARVALHO, M.S.S.; MILHOMEM, P.S.; SOUZA-LIMA, W. Bacias sedimentares brasileiras: Bacia de Tucano. Aracajú: Fundação Paleontológica Phoenix, 2003. (Série Bacias Sedimentares, n. 52).

PROSSER, S. Rift-related linked depositional systems and their seismic expression. In: Tectonics and Seismic Sequence Stratigraphy (Eds. WILLIAMS, G.D. \&. DOBB, A), Geological Society Special Publication, v. 71, p. 35-66, 1993.

SILVA, O.B.; CAIXETA, J.M.; MILHOMEM, P.S.; KOSIN, M.D. Bacia do Recôncavo. Boletim de Geociências da Petrobras - cartas estratigráficas, Rio de Janeiro, v. 15, n. 2, p. 423-431, 2007.

VAIL, P.R.; MITCHUM, Jr, R.; THOMPSON, III.S. Seismic Stratigraphy and Global Changes of Sea Level, Part 4: Global Cycles of Relative Changes of Sea Level, AAPG Special Volumes, 1977. doi.org/10.1306/M26490C5

VAIL, P.R. \& MITCHUM, Jr. R Seismic Stratigraphy and Global Changes of Sea Level, Part 1: Overview. 1977. https://doi.org/10.1306/M26490C3.

VIANA, C.F.; GAMA JUNIOR, E.G.; SIMÕES, I.A.; MOURA, J.A.; FONSECA, J.R.; ALVES, R.J. Revisão estratigráfica da Bacia do Recôncavo/Tucano. Boletim Técnico da Petrobras, Rio de Janeiro, v. 14, n. 3-4, p. 157-192, 1971.

VILAS BOAS, D.B.R. Correlação Sismoestratigráfica entre as Bacias do Recôncavo e de Camamu. Salvador, 2016. Tese (Mestrado em Geociências), Universidade Federal Da Bahia.

WIEDERKEHR, F. Arquitetura estratigráfica das formações Itaparica e Água Grande e seu posicionamento na evolução tectônica da Bacia do Recôncavo. Porto Alegre, 2010. Monografia (Graduação), Instituto de Geociências, Universidade Federal do Rio Grande do Sul. 